\title{
Antithrombotic Therapy in Atrial Fibrillation
}

Associated with Valvular Heart Disease: Executive

Summary of a Joint Consensus Document from the

European Heart Rhythm Association (EHRA) and

European Society of Cardiology Working Group on

Thrombosis, Endorsed by the ESC Working Group

on Valvular Heart Disease, Cardiac Arrhythmia

Society of Southern Africa (CASSA), Heart Rhythm

Society (HRS), Asia Pacific Heart Rhythm Society

(APHRS), South African Heart (SA Heart)

Association and Sociedad Latinoamericana de

Estimulación Cardíaca y Electrofisiología

(SOLEACE)

Gregory Y. H. Lip ${ }^{1,2}$ Jean Philippe Collet ${ }^{3}$ Raffaele de Caterina ${ }^{4}$ Laurent Fauchier $^{5}$ Deirdre A. Lane L $^{1,2}$ Torben B. Larsen ${ }^{6}$ Francisco Marin ${ }^{7}$ Joao Morais ${ }^{8}$ Calambur Narasimhan ${ }^{9}$ Brian Olshansky ${ }^{10}$ Luc Pierard $^{11}$ Tatjana Potpara ${ }^{12}$ Nizal Sarrafzadegan ${ }^{13,14}$ Karen Sliwa ${ }^{15,16}$ Gonzalo Varela ${ }^{17}$ Gemma Vilahur $^{18}$ Thomas Weiss ${ }^{19,20}$ Giuseppe Boriani21 ${ }^{21}$ Bianca Rocca ${ }^{22}$

${ }^{1}$ Institute of Cardiovascular Sciences, University of Birmingham, Birmingham, United Kingdom

2 Aalborg Thrombosis Research Unit, Department of Clinical

Medicine, Aalborg University, Aalborg, Denmark

${ }^{3}$ ACTION Study Group, Institut De Cardiologie, Hôpital Pitié-

Salpêtrière (APHP), Sorbonne Universite, Paris, France

${ }^{4}$ Institute of Cardiology, 'G. d'Annunzio' University, Chieti, Italy

${ }^{5}$ Centre Hospitalier Universitaire Trousseau et Faculté de Medicinde,

Université François Rabelais, Tours, France

6 Thrombosis Research Unit, Department of Clinical Medicine,

Aalborg University Hospital, Aalborg, Denmark

${ }^{7}$ Department of Cardiology, Hospital Universitario Virgen de la Arrixaca, Murcia, Spain

${ }^{8}$ Department of Cardiology, Leiria Hospital Centre, Leiria, Portugal

${ }^{9}$ Department of Cardiac Electrophysiology, CARE Hospital,

Hyderabad, Andhra Pradesh, India

${ }^{10}$ Clinical Cardiac Electrophysiology, Cardiology, Mercy Medical

Center, Mason City, lowa, United States

11 Department of Cardiology, University Hospital Sart-Tilman, Liege, Belgium

${ }^{12}$ Cardiology Clinic, Clinical Center of Serbia, University of Belgrade School of Medicine, Belgrade, Serbia

Thromb Haemost 2017;117:2215-2236.

received

October 10, 2017

accepted

October 10, 2017
${ }^{13}$ Isfahan Cardiovascular Research Center (WHO Collaborating (enter), Cardiovascular Research Institute, Isfahan University of Medical Sciences, Isfahan, Iran

${ }^{14}$ School of Population and Public Health, University of British Columbia, Vancouver, Canada

${ }^{15}$ Hatter Institute for Cardiovascular Research in Africa, Faculty of Health Sciences, University of Cape Town, South Africa

${ }^{16}$ Mary McKillop Institute, ACU, Melbourne, Australia

${ }^{17}$ Servicio de Electrofisiología, Centro Cardiovascular Casa de Galicia, Hidalgos, Uruguay

${ }^{18}$ Cardiovascular Science Institute (ICCC), CIBERCV, IIB-Sant Pau, Hospital de la Sant Pau, Barcelona, Spain

${ }^{19}$ Medical Department, Cardiology and Intensive Care Medicine, Wilhelminenhospital, Vienna, Austria

${ }^{20}$ Faculty of Medicine, Sigmund Freud University, Vienna, Austria

${ }^{21}$ Department of Cardiology, University of Modena and Reggio Emilia, Policlinico di Modena, Modena, Italy

${ }^{22}$ Institute of Pharmacology, Catholic University School of Medicine, Rome, Italy

Address for correspondence Gregory Y. H. Lip, Institute of Cardiovascular Sciences, University of Birmingham, Birmingham, United Kingdom (e-mail: g.y.h.lip@bham.ac.uk).

DOI https://doi.org/ 10.1160/TH-17-10-0709. ISSN 0340-6245. 


Abstract

Keywords
- atrial fibrillation
- valvular heart disease
- mitral stenosis
- mechanical
prosthetic heart
- valves
- thromboembolism
- stroke
- stroke prevention
- anticoagulation
- vitamin K antagonists
- NOACs

Management strategies for patients with atrial fibrillation (AF) in association with valvular heart disease (VHD) have been less informed by randomized trials, which have largely focused on 'non-valvular AF' patients. Thromboembolic risk also varies according to valve lesion and may also be associated with $\mathrm{CHA}_{2} \mathrm{DS}_{2}$-VASc score risk factor components, rather than only the valve disease being causal.

Given the need to provide expert recommendations for professionals participating in the care of patients presenting with AF and associated VHD, a task force was convened by the European Heart Rhythm Association (EHRA) and European Society of Cardiology (ESC) Working Group (WG) on Thrombosis, with representation from the ESC WG on Valvular Heart Disease, Heart Rhythm Society (HRS), Asia Pacific Heart Rhythm Society (APHRS), South African Heart (SA Heart) Association and Sociedad Latinoamericana de Estimulación Cardíaca y Electrofisiología (SOLEACE) with the remit to comprehensively review the published evidence, and to produce a consensus document on the management of patients with AF and associated VHD, with up-to-date consensus statements for clinical practice for different forms of VHD, based on the principles of evidence-based medicine.

This is an executive summary of a consensus document which proposes that the term 'valvular AF' is outdated and given that any definition ultimately relates to the evaluated practical use of oral anticoagulation (OAC) type, we propose a functional EHRA (Evaluated Heartvalves, Rheumatic or Artificial) categorization in relation to the type of OAC use in patients with AF, as follows: (1) EHRA (Evaluated Heartvalves, Rheumatic or Artificial) type $1 \mathrm{VHD}$, which refers to AF patients with ' $\mathrm{VHD}$ needing therapy with a vitamin K antagonist (VKA)' and (2) EHRA (Evaluated Heartvalves, Rheumatic or Artificial) type $2 \mathrm{VHD}$, which refers to AF patients with 'VHD needing therapy with a VKA or a non-VKA oral anticoagulant also taking into consideration $\mathrm{CHA}_{2} \mathrm{DS}_{2}$-VASc score risk factor components.

\section{Introduction}

Worldwide, atrial fibrillation (AF) in association with valvular heart disease (VHD) is relatively common, and management strategies for these patients have been less addressed by randomized clinical trials (RCTs). These RCTs have largely focused on 'non-valvular AF' leading to major uncertainties over how to define (and treat) such patients.

There is also an important heterogeneity in the definition of valvular and non-valvular AF. ${ }^{1}$ Some physicians assume that any valve disease should be considered as 'valvular' AF. Others consider that only mechanical valve prosthesis and mitral stenosis (MS) of rheumatic origin should be defined as 'valvular' AF.

The term 'valvular AF' has been arbitrarily applied and the 2016 ESC guidelines have avoided the term 'valvular AF' and refer simply to 'AF related to haemodynamically significant MS or prosthetic mechanical heart valves'. ${ }^{2}$ AF clearly leads to an incremental risk for thromboembolism (TE) in patients with mitral valve stenosis, but there are limited data on other valvular diseases, including mitral regurgitation (MR) or aortic valve disease. Another proposal is to use the acronym MARM-AF to designate 'mechanical and rheumatic mitral AF' as an alternative to the term 'valvular $\mathrm{AF}^{\prime}$ ' designating the clinical scenarios for which the non-vitamin $\mathrm{K}$ antagonist oral anticoagulants (NOACs) are not indicated. ${ }^{3}$

For this consensus document, we recognize the uncertainty in terminology, and our scope largely relates to AF associated with 'haemodynamically significant' rheumatic VHD (i.e. severe enough to impact on patient's survival or necessitate an intervention or surgery) or prosthetic mechanical heart valves. Nonetheless, TE risk varies according to valve lesion and may be associated with $\mathrm{CHA}_{2} \mathrm{DS}_{2}$-VASc score risk factor components, rather than the valve disease per se as being causal. ${ }^{4,5}$ TE risk may also be influenced not only by type but also by the severity of the lesion. For example, the degree of MR may matter when it comes to risk of $\mathrm{TE}$, as some studies suggest that mild (grade 1) MR is associated with a 2.7-fold increased risk of stroke/TE, while severe forms may possibly have a 'protective' effect (HR: 0.45 for stroke and 0.27 for left atrial stasis ${ }^{6}$ ). An appropriate definition of 'valvular AF' would need to identify a subgroup of patients with similar pathophysiology of TE, TE risk and treatment strategies. ${ }^{4,7}$

This is an executive summary of a consensus document which proposes that the term 'valvular AF' is outdated and given that any definition ultimately relates to the evaluated practical use of oral anticoagulation (OAC) type, we propose a functional EHRA (Evaluated Heartvalves, Rheumatic or Artificial) categorization in relation to the type of OAC use in 
patients with AF (see Summary box). This classification would have the advantage that it may easily evolve or be updated (type 1 may become type 2 or vice versa) when there are new results. For example, transcatheter mitral valve interventions (TMVI; e.g. to include both MitraClip and mitral valve replacement) are emerging as a possible therapeutic option, ${ }^{8}$ but more data are awaited especially in relation to OAC use. Also, EHRA type I is broadly similar to the previously described MARM-AF. ${ }^{3}$

\section{Summary box}

\begin{tabular}{|c|c|}
\hline Definition & $\begin{array}{l}\text { The term 'valvular AF' is } \\
\text { outdated and given that any } \\
\text { definition ultimately relates to } \\
\text { the evaluated practical use of } \\
\text { oral anticoagulation (OAC) type, } \\
\text { we propose a functional EHRA } \\
\text { (Evaluated Heartvalves, } \\
\text { Rheumatic or Artificial) } \\
\text { categorization in relation to the } \\
\text { type of OAC use in patients } \\
\text { with AF }\end{array}$ \\
\hline $\begin{array}{l}\text { EHRA (Evaluated Heartvalves, } \\
\text { Rheumatic or Artificial) type } 1 \\
\text { VHD, which refers to AF } \\
\text { patients with 'VHD needing } \\
\text { therapy with a vitamin K } \\
\text { antagonist (VKA)' }\end{array}$ & $\begin{array}{l}\text { - Mitral stenosis (moderate- } \\
\text { severe, of rheumatic origin) } \\
\text { - Mechanical prosthetic valve } \\
\text { replacement }\end{array}$ \\
\hline $\begin{array}{l}\text { EHRA (Evaluated Heartvalves, } \\
\text { Rheumatic or Artificial) type } 2 \\
\text { VHD, which refers to AF } \\
\text { patients with 'VHD needing } \\
\text { therapy with a VKA or a NOAC', } \\
\text { also taking into consideration } \\
\mathrm{CHA}_{2} \mathrm{DS}_{2} \text {-VASc score risk factor } \\
\text { components }\end{array}$ & $\begin{array}{l}\text { - Mitral regurgitation } \\
\text { - Mitral valve repair } \\
\text { - Aortic stenosis } \\
\text { - Aortic regurgitation } \\
\text { - Tricuspid regurgitation } \\
\text { - Tricuspid stenosis } \\
\text { - Pulmonary regurgitation } \\
\text { - Pulmonic stenosis } \\
\text { - Bioprosthetic valve } \\
\text { replacements } \\
\text { - Transaortic valve intervention } \\
\text { (TAVI) }\end{array}$ \\
\hline
\end{tabular}

A recent physician survey ${ }^{9}$ reported marked heterogeneity in the definition of valvular and non-valvular AF and variable management strategies, including NOACs in patients with VHD other than prosthetic heart valves or haemodynamically significant MS. While hypertrophic cardiomyopathy is sometimes discussed in association with valvular AF, this would not be addressed in this document, given specific guidelines on this condition. ${ }^{10}$

To address this topic, a task force was convened by the European Heart Rhythm Association (EHRA) and European Society of Cardiology (ESC) Working Group (WG) on Thrombosis, with representation from the ESC WG on Valvular Heart Disease, Heart Rhythm Society (HRS), Asia Pacific Heart Rhythm Society (APHRS), South African Heart (SA Heart) Association and Sociedad Latinoamericana de Estimulación Cardíaca y Electrofisiología (SOLEACE) with the remit to comprehensively review the published evidence, and to publish a joint consensus document on the management of patients with AF and associated VHD, with up-todate consensus statements for clinical practice.

\section{Evidence Review}

This document was prepared by the Task Force with representation from EHRA, HRS, APHRS and SOLAECE. The document was peer-reviewed by official external reviewers representing EHRA, HRS, APHRS, SOLAECE and WGs. Consensus statements are evidence based, and derived primarily from published data. In controversial areas, or with respect to issues without evidence other than usual clinical practice, a consensus was achieved by agreement of the expert panel after thorough deliberation.

Differently to guidelines, we opted for an easier and userfriendly system of ranking using 'coloured hearts' that should allow physicians to easily assess the current status of the evidence and consequent guidance (-Table 1). ${ }^{11}$ This EHRA grading of consensus statements does not have separate definitions of the level of evidence. This categorization, used for consensus statements, must not be considered as directly

Table 1 Scientific rationale of consensus statements ${ }^{\mathrm{a}}$

\begin{tabular}{|l|l|l|}
\hline Definitions related to a treatment or procedure & $\begin{array}{l}\text { Consensus statement } \\
\text { instruction }\end{array}$ & Symbol \\
\hline $\begin{array}{l}\text { Scientific evidence that a treatment or procedure is beneficial and } \\
\text { effective. Requires at least one randomized trial, or is supported by } \\
\text { strong observational evidence and authors' consensus. }\end{array}$ & 'Should do this' \\
\hline $\begin{array}{l}\text { General agreement and/or scientific evidence favour the usefulness / } \\
\text { efficacy of a treatment or procedure. May be supported by randomized } \\
\text { trials based on a small number of patients or which is not widely } \\
\text { applicable. }\end{array}$ & 'May do this' & 'Do not do this' \\
\hline $\begin{array}{l}\text { Scientific evidence or general agreement not to use or recommend a } \\
\text { treatment or procedure. }\end{array}$ & & \\
\hline
\end{tabular}

${ }^{a}$ This categorization for our consensus document should not be considered as being directly similar to that used for official society guideline recommendations. 
similar to that used for official society guideline recommendations, which apply a classification (classes I-III) and level of evidence (A, B and C) to recommendations.

Thus, a green heart indicates a 'should do this' consensus statement or indicated treatment or procedure that is based on at least one RCT, or is supported by strong observational evidence that it is beneficial and effective. A yellow heart indicates general agreement and/or scientific evidence favouring a 'may do this' statement or the usefulness/efficacy of a treatment or procedure. A 'yellow heart' symbol may be supported by RCTs based on a small number of patients or which is not widely applicable. Treatment strategies for which there is scientific evidence of potential harm and should not be used ('do not do this') are indicated by a red heart.

\section{Epidemiology of Valvular AF and Implications for Stroke/Thromboembolism}

Robust data on the epidemiology of patients with AF and associated VHD are limited. Examples of available data from some global registries and large trials are reported in -Supplementary Table S1 (online only). In the Randomized Evaluation of Long-Term Anticoagulation Therapy (RE-LY) AF registry which enrolled patients presenting to an emergency department with AF at 164 sites in 46 countries, rheumatic heart disease was present in $2.2 \%$ of North American patients, $21.5 \%$ of African patients and $31.5 \%$ of Indian patients. ${ }^{5}$ TE rates were related to clinical risk profile, as expressed by $\mathrm{CHADS}_{2}$ score, irrespective of the presence of rheumatic VHD. Detailed data on the geographic distribution of valvular AF are also reported in the - Supplementary Tables S2 and \$3 (online only).

\section{Pathophysiology: A Brief Overview}

The drivers of thrombogenesis in AF include the elements of the Virchow's triad: blood flow alterations, endocardial injury and changes in blood constituents. ${ }^{12,13}$ In fact, according to the recently published EHRA/HRS/APHRS/SOLAECE consensus document, atrial tissue in VHD is characterized, at a histopathological level, by a combination of cardiomyocyte and fibrotic changes. ${ }^{14}$ An overview of the pathophysiology of thrombogenesis in AF in haemodynamically significant MS and/or mechanical heart valves prosthesis is shown in - Fig. 1.

The risk of TE is increased in patients with AF and mechanical valve, mild-to-severe $\mathrm{MS}^{15}$ and left atrium dilatation, as compared with non-valvular $\mathrm{AF}^{4}{ }^{4}$ suggesting differences among the pathogenic mechanisms contributing to thrombosis in each of these AF conditions. It is generally thought that Virchow's triad is triggered by the turbulent flow and the endothelial injury that accompanies valvular AF. On top of this, AF prosthetic valves (particularly mechanical prosthesis) induce thrombin generation through the activation of both the tissue factor (TF) and the contact coagulation pathways. ${ }^{16}$ Surgical heart valve replacement surgery induces tissue damage with TF release leading to extrinsic coagulation pathway activation after binding to plasma factor (F) VII/FVIIa. Moreover, the exposure of valve leaflets, struts and/or sewing ring to the circulating blood ${ }^{17}$ can activate the contact (intrinsic) coagulation pathway. Both intrinsic and extrinsic pathways converge at the FX activation and then the transformation of prothrombin into thrombin (FIIa) and formation of the fibrin mesh. The vitamin K antagonist (VKA), warfarin, by blocking the formation of the vitamin $\mathrm{K}$-dependent clotting FVII, FIX, FX and FII, prevents the activation of the coagulation cascade at the extrinsic and intrinsic pathway levels.

In addition to the thrombogenic contribution of plasma coagulation in valvular AF, platelet activation may possibly contribute particularly to the mild-to-severe MS. Finally, acquired type IIA von Willebrand disease and bleeding complications can be associated with severe aortic stenosis (AS) due to high-molecular-weight multimer consumption. ${ }^{18}$

\section{Oral Anticoagulation with VKA in Patients with AF and Prosthetic Heart Valves, Including Bioprostheses}

\section{Mechanical Heart Valves}

Oral anticoagulation with VKA is crucial for the prevention of TE in patients with mechanical heart valves, regardless of the presence or absence of AF. The ESC guidelines ${ }^{19}$ establish the risk of TE in patients with mechanical valves according to valve type and position, and also according to the individual patient risk profile or comorbidities. Warfarin and other VKA are the most widely used OACs, and are titrated according to international normalized ratio (INR) range and target value which is also related with associated risk factors (- Table 2 ). ${ }^{20}$

The duration of antithrombotic therapy also varies according to several factors. Lifelong anticoagulant treatment is indicated with a class I recommendation for all patients with mechanical valves, and for those with bioprosthetic valves or native valve disease with $\geq 2$ additional stroke risk factors. ${ }^{2}$

\section{Bioprostheses}

Patients with bioprostheses and additional risk factors for systemic TE (AF, venous thrombosis, hypercoagulable state, or with a lesser degree of evidence, severely impaired left ventricular function) require lifelong OAC. The use of NOACs instead of warfarin in this setting is accepted by the more recent document of recommendations by EHRA ${ }^{21}$ despite of a lack of RCTs. ${ }^{22-24}$

After biological valve replacement, thromboembolic risk is estimated between 0.6 and $3.3 \%$ per year without anticoagulation, after the third month. ${ }^{25}$ The thromboembolic risk associated with a bioprosthesis and sinus rhythm is higher in the first 3 months after the surgery, the risk being almost eliminated in anticoagulated patients for aortic bioprosthesis, but remaining higher in patients with a mitral bioprosthesis. ${ }^{26,27}$ The benefit of an initial anticoagulant treatment following aortic valve replacement with a bioprosthesis and no AF is, however, debated. ${ }^{28-30}$

Overall, AF patients with a bioprosthesis had a non-significantly higher risk of stroke/TE events compared with patients with non-valvular AF, and VKA use was independently associated with a lower risk of thromboembolic events (hazard ratio: $0.83,95 \%$ confidence interval $[\mathrm{CI}]: 0.71-0.98) .{ }^{31}$ One small pilot study compared dabigatran versus warfarin after bioprosthesis valve replacement for the management of $\mathrm{AF}$ 


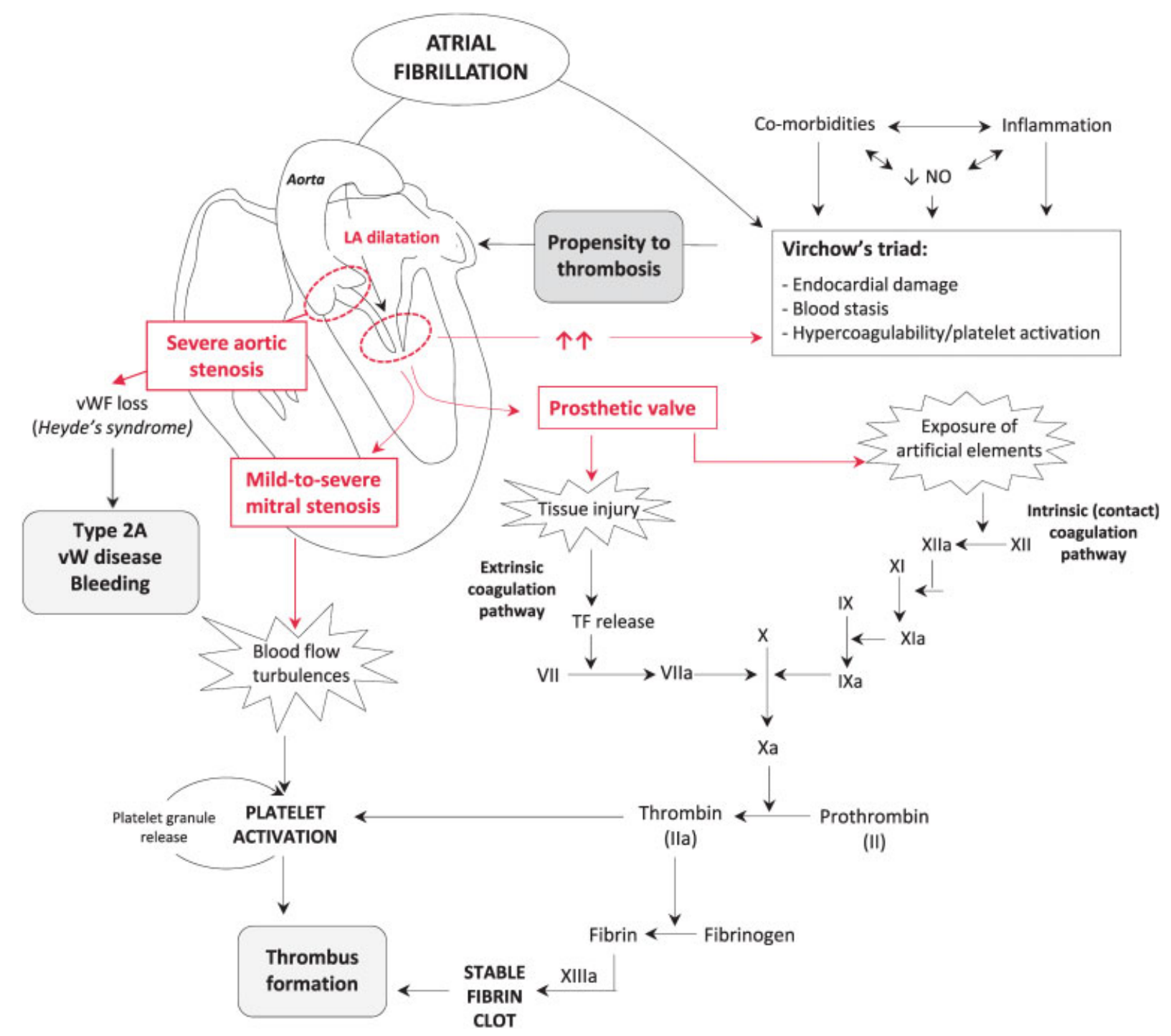

Fig. 1 Pathophysiology of thrombogenesis in atrial fibrillation (AF)-related prosthesis and/or mitral valve diseases. In valvular AF, there is a propensity to thrombosis because of the presence of the Virchow's triad components which, in turn, are found to be likely boosted by patients' comorbid conditions. The risk of thrombosis, however, is enhanced because of the presence of prosthetic valves which activate the coagulation cascade (both the intrinsic and extrinsic pathway) leading to thrombin production (a strong platelet agonist) and, although to a lesser extent, because of the considerable degree of mitral stenosis which induces flow turbulences capable of inducing platelet activation. Finally, AF also frequently occurs in patients with severe aortic stenosis, which can be associated with the Heyde syndrome due to von Willebrand factor (VWF) consumption leading to an acquired bleeding disorder.

postoperatively (DAWA pilot study), but small numbers preclude definitive conclusions. ${ }^{32}$

Recent small studies also suggest that NOACs can be a reasonable alternative to VKA in patients with AF and remote bioprosthetic valve implantation; 22,33 however, larger studies are needed to define the safety and efficacy profile. Data on thromboprophylaxis in patients with AF and TAVI, which is actually the insertion of a bioprosthesis, are preliminary ${ }^{34}$ and discussed in section 'Antithrombotic Therapy in Patients with AF Undergoing TAVI or Left Atrial Appendage Occlusion'.

Table 2 Target INR for mechanical prosthesis (some examples)

\begin{tabular}{|l|l|l|}
\hline $\begin{array}{l}\text { Prosthesis } \\
\text { thrombogenicity }\end{array}$ & Valve type & $\begin{array}{l}\text { Patient-related risk factors } \\
\text { (risk factor } \geq 1 \text { ) }\end{array}$ \\
\hline Low & $\begin{array}{l}\text { Carbomedics, Medtronic Hall, } \\
\text { St Jude Medical, ON-X }\end{array}$ & 3.0 \\
\hline Medium & Other bileaflet valves & 3.5 \\
\hline High & $\begin{array}{l}\text { Lillehei-Kaster, Omniscience, Starr-Edwards, } \\
\text { Bjork-Shiley and other tilting-disc valves }\end{array}$ & 4.0 \\
\hline
\end{tabular}

${ }^{a}$ Risk factors: previous thromboembolism, atrial fibrillation, mitral stenosis of any degree, left ventricular ejection fraction $<35 \%$. Source: Reproduced from Vahanian et al. ${ }^{20}$ 


\section{Mitral Valve Repair}

Patients undergoing mitral valve repair have a small risk of $\mathrm{TE}^{35}$ with the highest risk of TE occurring during the first year after surgery. Guidelines therefore recommend OAC during the first 3 to 6 months after the surgery. ${ }^{36}$ Only limited data are available on the efficacy of warfarin therapy in the early stages after valve surgery, and the use of shortterm VKAs in patients with mitral valve annuloplasty is also controversial. It is therefore not clear whether patients with AF in addition to valve repair are markedly different from the patients with AF in the absence of VHD. ${ }^{4,16}$

North American and European guidelines have a different position on this issue: the former considering AF in association with valve repair as 'valvular AF', while ESC guidelines do not do so. ${ }^{28,37}$

\section{Consensus statements:}

\begin{tabular}{|c|c|c|}
\hline & $\begin{array}{l}\text { Coloured } \\
\text { heart }\end{array}$ & $\begin{array}{l}\text { Supporting } \\
\text { references }\end{array}$ \\
\hline $\begin{array}{l}\text { Well-managed VKA } \\
\text { monotherapy with good } \\
\text { anticoagulation control (e.g. } \\
\text { time in therapeutic range } \\
>65-70 \%) \text { is generally } \\
\text { recommended, taking into } \\
\text { account the type of valve, } \\
\text { the position and additional } \\
\text { risk factor(s), including atrial } \\
\text { fibrillation. }\end{array}$ & & 20 \\
\hline $\begin{array}{l}\text { - Patients with a bioprosthetic } \\
\text { valve and atrial fibrillation } \\
\text { require lifelong OAC. }\end{array}$ & & \\
\hline
\end{tabular}

\section{Indications of 'Add-on' Antiplatelet Therapy in Patients with AF and Prosthetic Mechanical Heart Valves}

Arterial TE and valve thrombosis are approximately $12 \% /$ year and $22 \% / y e a r$, for mechanical valve prosthesis in the aortic and mitral position, respectively, in patients without VKA prophylaxis. ${ }^{25}$ The residual risk ranges from $0.5 \% /$ year to $2.5 \% /$ year, $25,38-40$ in VKA-treated patients without additional cardiovascular risk factors such as AF. A higher incidence is associated with the mitral ( $\sim 2 \% /$ year) versus the aortic $(\sim 1 \% /$ year) position, depending also on the type of valve and VKA intensity. ${ }^{25,39,40} \mathrm{AF}$ and/or other risk factors (e.g. heart failure, even without AF) increase TE risk by fourfold, from 4 up to $8 \% / y e a r, 37,41,42$ even on adequate VKA treatment. ${ }^{41,42}$

Given this high-residual TE risk, RCTs have compared VKA alone versus VKA combined with different aspirin doses and/ or dipyridamole $25,43,44$ ( - Table 3).

Despite major methodological limitations of these studies including small sample size, heterogeneities in thrombotic risk level at study entry and anticoagulation intensity, as well as inconsistencies in safety and efficacy endpoint definitions, ${ }^{43}$ there may possibly be some benefit of adding low-dose aspirin (between 75 and 200 mg daily) to VKA in patients with mechanical valve prosthesis and additional risk factors including
$\mathrm{AF}^{25,43,45}$ (- Table 3). This approach lowered TE complications in the majority of studies, ${ }^{25,41-43,46}$ and two meta-analyses showed approximately $60 \%$ relative risk reduction (RRR) of TE and approximately 50\% RRR of all-cause mortality ${ }^{43,44}$ (-Table 3). Nonetheless, the relative risk of major bleeding with VKAs plus antiplatelet therapy increases by approximately $58 \%$ across studies including aspirin daily doses from 100 to $1,000 \mathrm{mg}^{43,44}$ and high-dose dipyridamole alone or with aspirin. ${ }^{43}$ Importantly, major bleeding appears significantly affected by aspirin dose: the association with low dose (100 mg) shows a bleeding risk significantly lower than higher doses $^{43,47}$ and not significantly different from VKA alone (odds ratio $[\mathrm{OR}]=0.96$; 95\% confidence interval $[\mathrm{CI}]$ : 0.60-1.55; 2.58; 95\% CI: $1.43-2.55$ for low and high doses versus VKA, respectively, $p=0.002$ for the high-dose aspirin combination versus VKA) with similar efficacy (- Table 3). ${ }^{43,47}$ Thus, VKA plus lowdose aspirin (75-100 mg daily) for the association of mechanical prosthetic valve and AF is recommended by the AHA/ASA/ACCP as a class I (level A or B) recommendation, ${ }^{38,40,48,49}$ but as a class IIb $C$ recommendation by the ESC.

When the aspirin/VKA combination is used, anticoagulation should be titrated taking into account the type of valve, the position and comorbidities. The target INR for AF patients with aortic mechanical prosthetic valve on VKA and lowdose aspirin should be 2.5 (range: 2.0-3.0), with close attention to the quality of anticoagulation control, with time in therapeutic range (TTR) $>65$ to $70 \%$.

Whether the INR target should be 2.5 (range: $2-3$ ) or 3 (range: 2.5-3.5) in AF patients with mitral prosthetic valve on both VKA and low-dose aspirin is less clear. High-intensity VKA (i.e. INR range: 3-4 or higher), combined with aspirin, has been consistently associated with higher major bleeding and comparable benefit as lower intensity VKA with aspirin. ${ }^{50-52}$

\section{Consensus statements:}

\begin{tabular}{|c|c|c|}
\hline & $\begin{array}{l}\text { Coloured } \\
\text { heart }\end{array}$ & $\begin{array}{l}\text { Supporting } \\
\text { references }\end{array}$ \\
\hline $\begin{array}{l}\text { - In patients with a mechanical } \\
\text { prosthetic valve and } \\
\text { concomitant AF with vascular } \\
\text { disease, VKA plus low-dose } \\
\text { aspirin ( } 75-100 \text { mg daily) } \\
\text { may be considered in the } \\
\text { absence of high bleeding risk. }\end{array}$ & & $\begin{array}{l}38,43,45-47 \\
49,52\end{array}$ \\
\hline $\begin{array}{l}\text { - In patients with a mechanical } \\
\text { prosthetic valve and AF, when } \\
\text { VKA plus aspirin is used, the } \\
\text { INR should be kept between } \\
2.0 \text { and } 3.0 \text { (target } 2.5 \text { ), } \\
\text { given the high bleeding risk } \\
\text { of the combination and the } \\
\text { lack of evidence of greater } \\
\text { protection with higher } \\
\text { intensity VKA (INR range: } \\
3-5 \text { or above). }\end{array}$ & & $49-51$ \\
\hline $\begin{array}{l}\text { - High doses of aspirin } \\
(\geq 325 \mathrm{mg}) \text { in association } \\
\text { with VKA at any intensity } \\
\text { must be avoided. }\end{array}$ & & $43,47,52$ \\
\hline
\end{tabular}




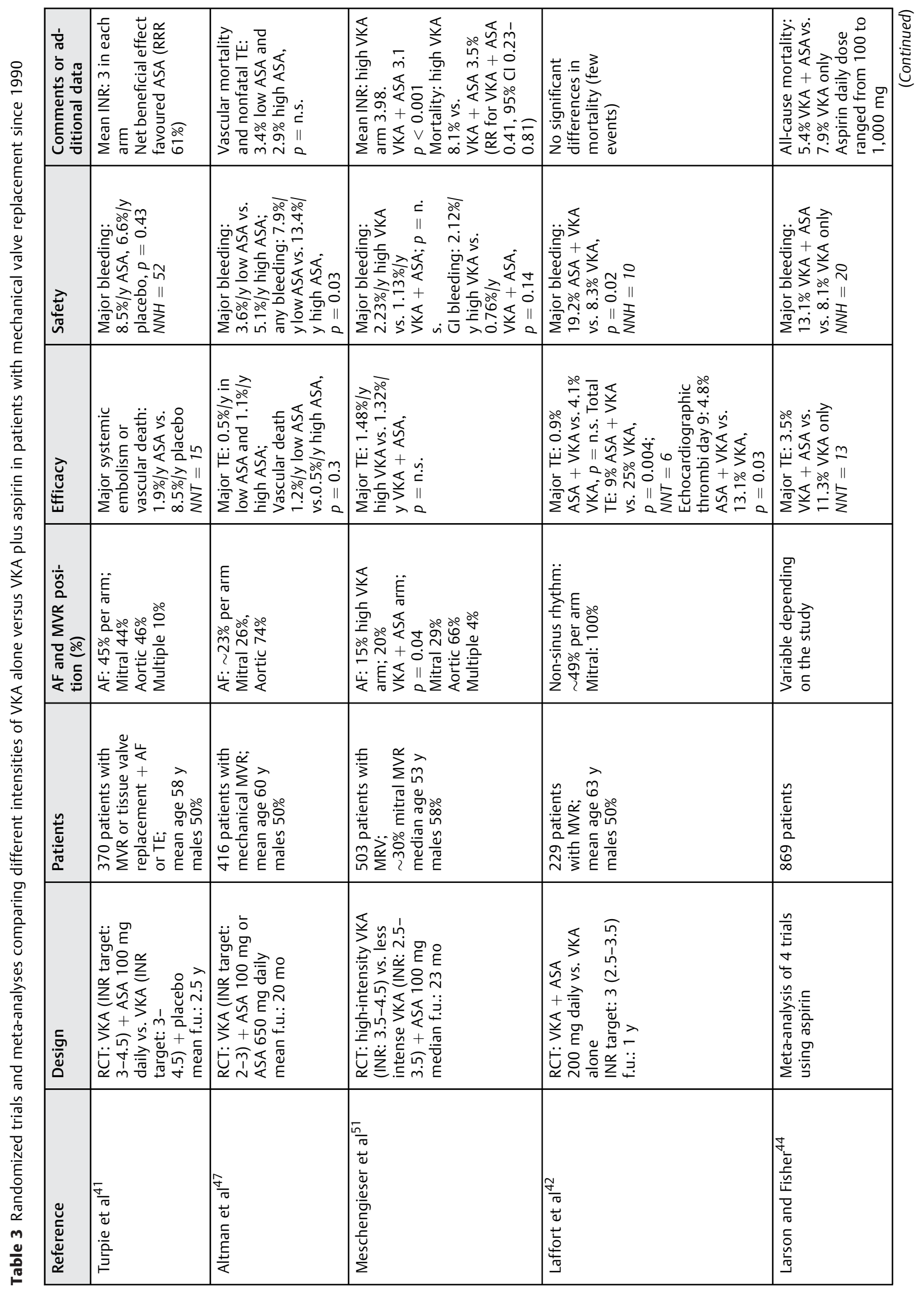




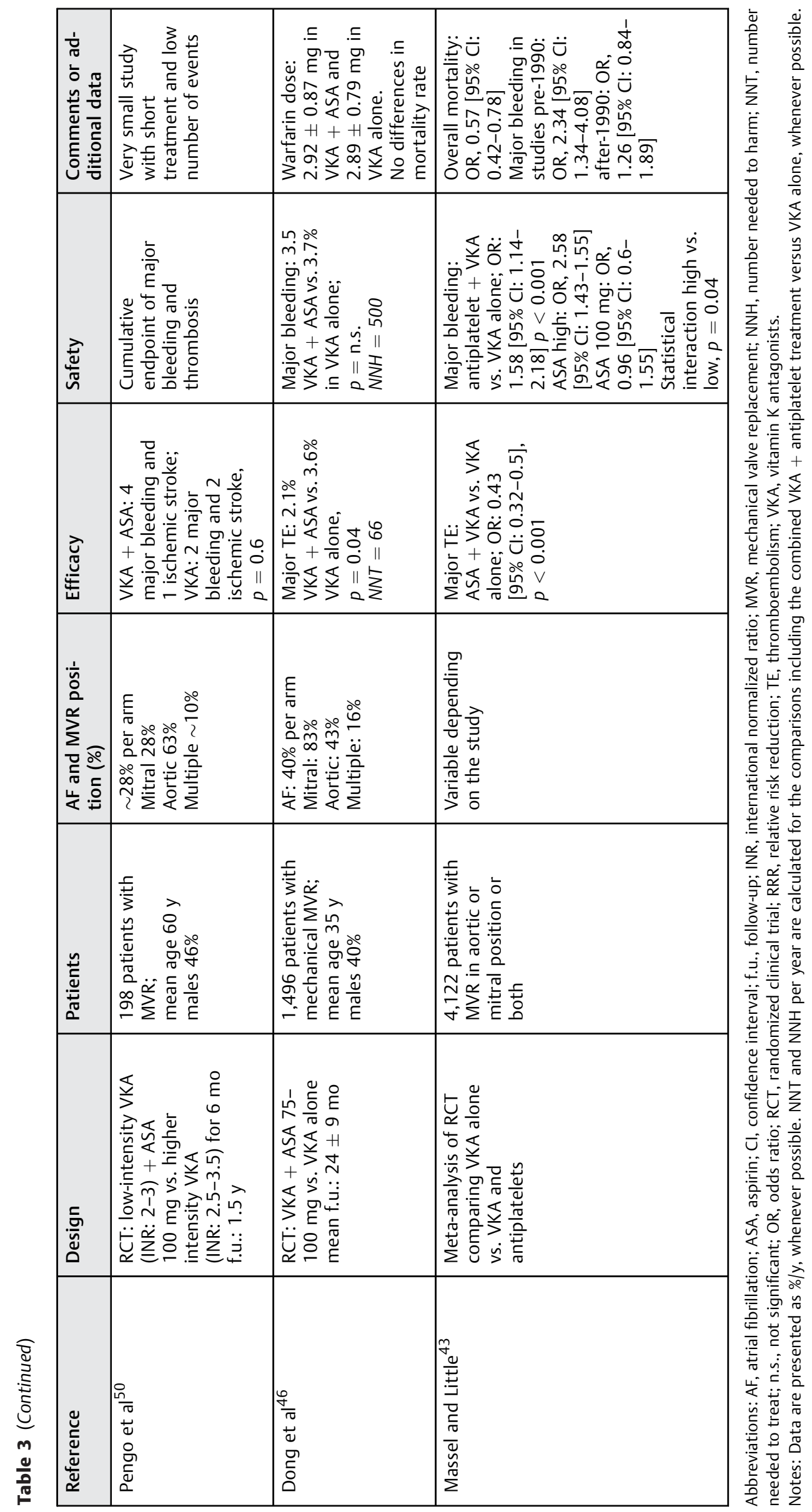




\section{Evidence for NOACs Use in Patients with AF and VHD}

\section{Subgroups from the Recent NOAC Trials}

The efficacy and safety of NOACs for the prevention of stroke/ systemic embolic events (SSEE) in patients with non-valvular AF has been established by the pivotal RCTs. ${ }^{53-57}$ These trials excluded patients with significant MS or prosthetic mechanical valves but enrolled participants (13-26\%, depending on the trial) $)^{24,58-60}$ with other clinically significant non-rheumatic VHD, including MR, aortic regurgitation (AR), AS, mild MS or prior valve surgery (bioprosthetic valves or valve repair) (-Table 4). There are limited or no data on other options, such as MitraClip or other TMVI, and thus NOACs should not be used in these patients.

Variable inclusion/exclusion criteria across the NOACs trials reflect the prevailing lack of a clear-cut definition of valvular $\mathrm{AF}^{4}$ Patients with VHD of non-rheumatic origin are prevalent in clinical practice, ${ }^{61}$ and physicians may often deny NOACs to eligible AF patients due to uncertainty over whether the patient has valvular or non-valvular $\mathrm{AF}^{1}{ }^{1}$

There are no RCTs on NOACs in AF patients with VHD. In the RE-LY ${ }^{58}$ Rivaroxaban Once Daily Oral Direct Factor Xa Inhibition Compared with Vitamin K Antagonism for Prevention of Stroke and Embolism Trial in Atrial Fibrillation (ROCKET-AF), ${ }^{59}$ Apixaban for Reduction in Stroke and Other Thromboembolic Events in Atrial Fibrillation (ARISTOTLE) ${ }^{60}$ and Effective Anticoagulation with factor Xa Next Generation in Atrial FibrillationThrombolysis in Myocardial Infarction 48 (ENGAGE AF-TIMI $48)^{24}$ trial subgroup analyses, non-valvular AF patients with VHD were older, had more comorbidities (including renal dysfunction), more persistent/permanent AF and higher cardioembolic and bleeding risks than patients without VHD. While the use of aspirin was broadly similar, prior VKA use was more common among patients with VHD. Irrespective of the treatment arm (i.e. warfarin or a NOAC), VHD patients generally experienced worse outcomes (stroke and systemic TE, major bleeding or all-cause death) in comparison to non-VHD patients ( - Table 5). Nonetheless, the efficacy of NOACs in reduction of SSEE or all-cause mortality was consistent among patients without or with VHD (irrespective of the VHD subtype). Likewise, the safety of NOACs in terms of lower risk of major bleeding or ICH was consistent irrespective of VHD status, excluding the significantly higher rates of major bleeding in VHD patients (particularly those with AS, or MR or AR) ${ }^{62}$ treated with rivaroxaban compared with warfarin (-Table 5). Importantly, there are no head-to-head comparisons for any NOAC versus VKA in AF patients with moderate-to-severe MS; as

Table 4 Inclusion/exclusion criteria pertinent to valvular heart disease in the pivotal NOAC trials in patients with 'non-valvular' AF and valvular disease-type distribution across the trials

\begin{tabular}{|c|c|c|c|c|c|}
\hline Inclusion $(\sqrt{ }) /$ exclusion $(-)$ criteria & RE-LY ${ }^{53}$ & ROCKET-AF $^{54}$ & ARISTOTLE $^{55}$ & ENGAGE-AF $^{56}$ & AVERROES $^{57}$ \\
\hline \multicolumn{6}{|l|}{ Prosthetic heart valve(s) } \\
\hline - Mechanical & - & - & - & - & - \\
\hline - Bioprosthesis & - & - & $\sqrt{ }$ & $\sqrt{ }$ & $\sqrt{ }$ \\
\hline Prior surgical repair ${ }^{a}$ & - & $\sqrt{ }$ & $\sqrt{ }$ & $\sqrt{ }$ & $\sqrt{ }$ \\
\hline Moderate-to-severe MS & - & - & - & - & - \\
\hline Other significant valve disease ${ }^{b}$ & - & $\sqrt{ }$ & $\sqrt{ }$ & $\sqrt{ }$ & - \\
\hline Mild-to-moderate valve disease & $\sqrt{ }$ & $\sqrt{ }$ & $\sqrt{ }$ & $\sqrt{ }$ & $\sqrt{ }$ \\
\hline Subgroups with a cardiac valve disease ${ }^{c}$ & RE-LY ${ }^{58}$ & ROCKET-AF $^{59}$ & ARISTOTLE $^{60}$ & ENGAGE-AF $^{24}$ & \\
\hline Total number (\%) & $3,950(21.8)$ & $2,003(14.1)$ & $4,808(26.4)$ & $2,824(13.4)$ & NR \\
\hline Moderate/severe MR & $3,101(78.5)$ & $1,756(87.7)$ & $3,526(73.3)$ & $2,250(79.6)$ & NR \\
\hline Moderate/severe AR & $817(20.7)$ & $486(24.3)$ & $887(18.4)$ & $369(13.0)$ & $\mathrm{NR}$ \\
\hline Moderate/severe AS & 471 (11.9) & $215(10.7)$ & $384(8.0)$ & $165(5.8)$ & NR \\
\hline Other & $1,179(6.5)$ & $11(0.6)^{d}$ & $2,124(44.2)$ & NR & NR \\
\hline Mild MS & $193(4.9)$ & NR & $131(2.7)$ & $254(9.0)$ & $\mathrm{NR}$ \\
\hline $\begin{array}{l}\text { Prior valve surgery (excluding mechanic } \\
\text { prosthetic heart valve) }\end{array}$ & Not applicable & $106(5.3)$ & $251(5.2)$ & $325(11.5)$ & NR \\
\hline Valve repair & - & $42(2.1 \%)$ & NR & $123(4.3)$ & NR \\
\hline Valvuloplasty & - & $64(3.2 \%)$ & NR & $19(0.7)$ & NR \\
\hline Bioprosthetic valves & - & Not applicable & $82(1.7)$ & $191(6.8)$ & NR \\
\hline
\end{tabular}

Abbreviations: AF, atrial fibrillation; AR, aortic regurgitation; AS, aortic stenosis; MR, mitral regurgitation; MS, mitral stenosis; NOAC, non-vitamin $\mathrm{K}$ antagonist oral anticoagulant; NR, not reported.

${ }^{a}$ Annuloplasty, commissurotomy, valvuloplasty, etc.

${ }^{\mathrm{b}}$ Clinically significant, but not requiring immediate surgery repair.

${ }^{c}$ Categories are not mutually exclusive.

dWithout any of the preceding. 
Table 5 Major outcomes in AF patients by valvular heart disease status and treatment

\begin{tabular}{|c|c|c|c|c|c|c|}
\hline Outcome trial & NOAC/Warfarin & $\begin{array}{l}\text { VHD } \\
\text { (rate \%/y) }\end{array}$ & $\begin{array}{l}\text { Non-VHD } \\
\text { (rate \%/y) }\end{array}$ & $\begin{array}{l}\text { VHD } \\
\text { NOAC vs. warfarin } \\
\text { HR }(95 \% \mathrm{Cl})\end{array}$ & $\begin{array}{l}\text { Non-VHD } \\
\text { NOAC vs. warfarin } \\
\text { HR }(95 \% \mathrm{Cl})\end{array}$ & $\begin{array}{l}\text { Interaction } \\
p\end{array}$ \\
\hline \multicolumn{7}{|l|}{ Stroke/SE } \\
\hline ROCKET-AF ${ }^{59}$ & Rivaroxaban/Warfarin & $2.01 / 2.43$ & $1.96 / 2.22$ & $0.83(0.55-1.27)$ & $0.89(0.75-1.07)$ & 0.70 \\
\hline ARISTOTLE $^{60}$ & Apixaban/Warfarin & $1.46 / 2.08$ & $1.20 / 1.43$ & $0.70(0.51-0.97)$ & $0.84(0.67-1.04)$ & 0.378 \\
\hline \multirow[t]{2}{*}{ RE-LY ${ }^{58}$} & Dabi-150 mg/Warfarin & $1.12 / 1.90$ & $1.11 / 1.66$ & $0.59(0.37-0.93)$ & $0.67(0.52-0.86)$ & 0.63 \\
\hline & Dabi-110 mg/Warfarin & $1.84 / 1.90$ & $1.45 / 1.66$ & $0.97(0.65-1.45)$ & $0.88(0.70-1.10)$ & 0.65 \\
\hline ENGAGE-AF $^{24}$ & $\begin{array}{l}\text { HDER/Warfarin } \\
\text { LDER/Warfarin }\end{array}$ & $\begin{array}{l}1.39 / 2.02 \\
1.94 / 2.02\end{array}$ & $\begin{array}{l}1.60 / 1.77 \\
2.04 / 1.77\end{array}$ & $\begin{array}{l}0.69(0.44-1.07) \\
0.97(0.66-1.44)\end{array}$ & $\begin{array}{l}0.91(0.77-1.07) \\
1.15(0.98-1.35)\end{array}$ & $\begin{array}{l}0.255 \\
0.440\end{array}$ \\
\hline $\begin{array}{l}\text { ARISTOTLE }{ }^{72} \text { bioprosthetic } \\
\text { valves }(n=82)\end{array}$ & Apixaban/Warfarin & $2.9 / 0.0$ & $\mathrm{NA}$ & NR & NA & - \\
\hline \multirow{2}{*}{$\begin{array}{l}\text { ENGAGE-AF }{ }^{22} \text { bioprosthetic } \\
\text { valves }(n=191)\end{array}$} & HDER/Warfarin & $1.19 / 1.66$ & NA & $0.37(0.10-1.42)$ & NA & 0.15 \\
\hline & LDER/Warfarin & $2.57 / 1.66$ & NA & $0.53(0.16-1.78)$ & NA & 0.31 \\
\hline \multicolumn{7}{|l|}{ Major bleeding } \\
\hline ROCKET-AF $^{59}$ & Rivaroxaban/Warfarin & $6.14 / 4.20$ & $3.22 / 3.33$ & $1.56(1.14-2.14)$ & $0.98(0.84-1.15)$ & 0.01 \\
\hline ARISTOTLE ${ }^{60}$ & Apixaban/Warfarin & $2.49 / 3.14$ & $2.01 / 3.07$ & $0.79(0.61-1.04)$ & $0.65(0.55-0.77)$ & 0.23 \\
\hline \multirow[t]{2}{*}{ RE-LY ${ }^{58}$} & Dabi-150 mg/Warfarin & $4.21 / 5.12$ & $3.06 / 3.14$ & $0.82(0.64-1.06)$ & $0.98(0.83-1.15)$ & 0.25 \\
\hline & Dabi-110 mg/Warfarin & $3.77 / 5.12$ & $2.63 / 3.14$ & $0.73(0.56-0.95)$ & $0.84(0.71-0.99)$ & 0.38 \\
\hline ENGAGE-AF $^{24}$ & $\begin{array}{l}\text { HDER/Warfarin } \\
\text { LDER/Warfarin }\end{array}$ & $\begin{array}{l}3.28 / 4.46 \\
1.82 / 4.46\end{array}$ & $\begin{array}{l}2.66 / 3.27 \\
1.59 / 3.27\end{array}$ & $\begin{array}{l}0.74(0.53-1.02) \\
0.41(0.28-0.60)\end{array}$ & $\begin{array}{l}0.82(0.71-0.94) \\
0.49(0.41-0.57)\end{array}$ & $\begin{array}{l}0.573 \\
0.439\end{array}$ \\
\hline $\begin{array}{l}\text { ARISTOTLE bioprosthetic } \\
\text { valves }(n=82)^{76}\end{array}$ & Apixaban/Warfarin & $7.9 / 5.2$ & NA & NR & NA & 0.61 \\
\hline \multirow{2}{*}{$\begin{array}{l}\text { ENGAGE-AF } 22 \text { bioprosthetic } \\
\text { valves }(n=191)\end{array}$} & HDER/Warfarin & NR & NA & $0.50(0.15-1.67)$ & NA & 0.26 \\
\hline & LDER/Warfarin & $0.76 / 6.27$ & $\mathrm{NA}$ & $0.12(0.01-0.95)$ & NA & 0.045 \\
\hline \multicolumn{7}{|l|}{$\mathrm{ICH}^{\mathrm{a}}$} \\
\hline ROCKET-AF ${ }^{59}$ & Rivaroxaban/Warfarin & $0.88 / 0.73$ & $0.43 / 0.74$ & $1.27(0.58-2.79)$ & $0.59(0.40-0.86)$ & 0.084 \\
\hline ARISTOTLE $^{60}$ & Apixaban/Warfarin & $0.25 / 0.88$ & $0.37 / 0.78$ & $0.28(0.14-0.57)$ & $0.47(0.33-0.68)$ & 0.20 \\
\hline \multirow[t]{2}{*}{ RE-LY ${ }^{58}$} & Dabi-150 mg/Warfarin & $0.34-0.93$ & $0.31 / 0.72$ & $0.36(0.17-0.77)$ & $0.43(0.28-0.67)$ & 0.68 \\
\hline & Dabi-110 mg/Warfarin & $0.27 / 0.93$ & $0.21 / 0.72$ & $0.29(0.13-0.68)$ & $0.30(0.18-0.49)$ & 0.98 \\
\hline ENGAGE-AF $^{24}$ & $\begin{array}{l}\text { HDER/Warfarin } \\
\text { LDER/Warfarin }\end{array}$ & $\begin{array}{l}0.32 / 0.82 \\
0.24 / 0.82\end{array}$ & $\begin{array}{l}0.41 / 0.85 \\
0.26 / 0.85\end{array}$ & $\begin{array}{l}0.39(0.15-0.98) \\
0.29(0.11-0.79)\end{array}$ & $\begin{array}{l}0.48(0.35-0.66) \\
0.31(0.21-0.45)\end{array}$ & $\begin{array}{l}0.657 \\
0.926\end{array}$ \\
\hline \multicolumn{7}{|l|}{ All-cause mortality } \\
\hline ROCKET-AF ${ }^{59}$ & Rivaroxaban/Warfarin & $5.48 / 5.60$ & $4.19 / 4.60$ & $0.98(0.75-1.29)$ & $0.91(0.80-1.03)$ & 0.60 \\
\hline ARISTOTLE $^{60}$ & Apixaban/Warfarin & $4.95 / 4.88$ & $3.02 / 3.61$ & $1.01(0.84-1.22)$ & $0.84(0.73-0.96)$ & 0.101 \\
\hline \multirow[t]{2}{*}{ RE-LY ${ }^{58}$} & Dabi-150 mg/Warfarin & $4.28 / 4.73$ & $3.46 / 3.96$ & $0.91(0.70-1.17)$ & $0.87(0.75-1.01)$ & 0.79 \\
\hline & Dabi-110 mg/Warfarin & $4.35 / 4.73$ & $3.58 / 3.96$ & $0.92(0.71-1.19)$ & $0.90(0.78-1.04)$ & 0.89 \\
\hline ENGAGE-AF $^{24}$ & $\begin{array}{l}\text { HDER/Warfarin } \\
\text { LDER/Warfarin }\end{array}$ & $\begin{array}{l}6.46 / 5.71 \\
5.81 / 5.71\end{array}$ & $\begin{array}{l}3.62 / 4.13 \\
3.46 / 4.13\end{array}$ & $\begin{array}{l}1.13(0.90-1.41) \\
1.03(0.82-1.29)\end{array}$ & $\begin{array}{l}0.88(0.78-0.98) \\
0.83(0.75-0.93)\end{array}$ & $\begin{array}{l}0.045 \\
0.100\end{array}$ \\
\hline $\begin{array}{l}\text { ARISTOTLE bioprosthetic } \\
\text { valves }(n=82)^{76}\end{array}$ & Apixaban/Warfarin & $6.9 / 7.1$ & NA & NR & NA & 0.88 \\
\hline \multirow{2}{*}{$\begin{array}{l}\text { ENGAGE-AF } 22, a \text { bioprosthetic } \\
\text { valves }(n=191)\end{array}$} & HDER/Warfarin & NR & $\mathrm{NA}$ & $0.46(0.23-0.91)$ & NA & 0.03 \\
\hline & LDER/Warfarin & NR & NA & $0.43(0.21-0.88)$ & NA & 0.02 \\
\hline
\end{tabular}

Abbreviations: HDER, higher dose edoxaban regimen; ICH, intracranial haemorrhage; LDER, lower dose edoxaban regimen; NA, not applicable; NOACS, non-vitamin K oral anticoagulants; NR, not reported; SE, systemic embolism; VHD, valvular heart disease.

Note: There was no effect of modification of the presence or absence of VHD on relative outcomes with HDER or LDER in comparison to warfarin (all interaction $p$ were non-significant).

an the sub-analyses including only bioprosthetic valves, the rates of ICH were not specified: composite outcome of stroke/SE, major bleeding or death. 
mentioned earlier, these patients were not enrolled in the NOACs trials.

The number of patients with any prior valve surgery (i.e. bioprosthetic valves or valve repair) exposed to rivaroxaban, apixaban or edoxaban in the ROCKET-AF, ARISTOTLE or ENGAGE AF-TIMI 48 trials, respectively, was very low (-Table 4). Nevertheless, as reported for apixaban and edoxaban, ${ }^{22,23}$ there was no statistically significant interaction between the presence of a bioprosthetic heart valve and the respective NOAC effects ( - Table $\mathbf{5}$ ), thus suggesting that apixaban or edoxaban may possibly be alternatives to warfarin in AF patients with bioprosthetic valves implanted $\geq 3$ months ago.

A meta-analysis of the VHD subgroups from the RE-LY, ROCKET-AF, ARISTOTLE and ENGAGE AF-TIMI 48 trials $^{22}$ broadly confirmed the findings shown in -Table 5 . Overall, AF patients with VHD had non-significantly higher rate of SSEE (RR: 1.13; 95\% CI: 0.99-1.28) and significantly higher rates of major bleeding (RR: $1.34 ; 95 \% \mathrm{CI}: 1.13-1.49$ ) and allcause death (RR: $1.34 ; 95 \% \mathrm{CI}: 1.13-1.59)$ than patients without VHD.

Compared with warfarin, the use of NOACs (i.e. rivaroxaban, apixaban or higher doses of dabigatran or edoxaban) was associated with consistently lower rates of SSEE regardless of the presence or absence of VHD (RR: 0.70; 95\% CI: $0.58-0.86$ and 0.84 ; $95 \% \mathrm{CI}: 0.75-0.95$, respectively; interaction $p=0.31$ ), similar major bleeding rates (VHD RR: 0.93; 95\% CI: 0.67-1.27 and non-VHD RR: 0.85; 95\% CI: 0.70-1.02, interaction $p=0.63$ ), consistently lower rates of ICH (VHD RR: 0.47 ; $95 \%$ CI: $0.24-0.93$ and non-VHD RR: $0.49 ; 95 \%$ CI: $0.41-0.59$, interaction $p=0.91)$ and higher all-cause death rate in VHD patients (RR 1.01; 95\% CI, 0.90-1.14) than in those without VHD (RR $0.88 ; 95 \% \mathrm{CI}, 0.82-0.94$, interaction $p=0.03) .{ }^{63}$ In the analysis that also included the lower doses of dabigatran and edoxaban, the magnitude of SSEE risk reduction with NOACs versus warfarin was slightly reduced, as well as the rates of major bleeding and ICH, but there were no significant subgroup interactions by VHD status. Overall, the presence of VHD did not affect the relative protective effect of NOACs compared with warfarin in terms of SSEE and major bleeding. These findings were further supported by another meta-analysis of the four NOACs yielding identical results. ${ }^{22,64}$ of note, both meta-analyses reported significant treatment effect heterogeneity regarding major bleeding in both the VHD and non-VHD analyses.

With the exclusion of patients with moderate-to-severe MS, prosthetic mechanical heart valve, TAVI or TMVI, who were not enrolled in the non-valvular AF trials, the aforementioned subgroup and meta-analyses may suggest that $\mathrm{AF}$ patients with VHD would experience at least the same benefit from NOACs as patients without VHD. However, due to limitations inherent to these types of analyses, further RCTs are required in AF patients with VHD before recommendations can be given (see $\boldsymbol{-}$ Tables $\mathbf{4}$ and $\mathbf{5}$ ).

\section{Prosthetic Mechanical Heart Valves}

Mechanical valve prostheses trigger complex mechanisms of thrombogenesis and are associated with a very high cardi- oembolic risk requiring chronic OAC even in the absence of AF. Animal studies on mechanical valve implantation using first the direct FIla inhibitors melagatran ${ }^{65}$ and then dabiga$\operatorname{tran}^{66,67}$ as well as the phase III data from the RE-LY trial ${ }^{53}$ informed the only study to date on a NOAC in patients with mechanical heart valves.

The Randomized, Phase II Study to Evaluate the Safety and Pharmacokinetics of Oral Dabigatran Etexilate in Patients after Heart Valve Replacement (RE-ALIGN) trial was a phase-II, controlled, dose-finding, open-label study ${ }^{68}$ randomizing (2:1) patients with aortic $(n=172 ; 68 \%)$ or mitral $(n=71$; $28 \%)$ mechanical valve replacement, or both $(n=9 ; 4 \%)$ to dabigatran or adjusted-dose warfarin (target INR: 2.0-3.0 or 2.5-3.5 in aortic or mitral position, respectively). The initial dabigatran dose of 150,220 or $300 \mathrm{mg}$ twice daily (bid) (selected according to renal function) was further adjusted over 12 weeks to achieve the primary study outcome-a trough plasma concentration of $\geq 50 \mathrm{ng} / \mathrm{mL}$, based on the pharmacokinetic model from the RE-LY trial. Most patients (79\%) received study drug 5 to 7 days after the surgery, and $23 \%$ of patients had AF. The RE-ALIGN study was prematurely terminated after randomizing 252 of 405 planned patients, due to an excess in stroke ( 5 vs. $0 \%$ ), valve thrombosis ( 3 vs. $0 \%$ ) and major bleeding events ( 4 vs. $2 \%$ ) in the dabigatran arm, after a mean dabigatran exposure of $\sim 20$ weeks. Different explanations have been proposed, including inadequate dabigatran plasma concentrations, different pharmacodynamics of dabigatran and warfarin, excessive activation of the contact coagulation pathway induced by the sewing ring in the early postoperative course, a higher inter-individual variability in the dabigatran arm and differences in predicted versus observed drug concentrations in the RE-LY versus RE-ALIGN. ${ }^{68} \mathrm{~A}$ recent in vitro study suggested that the dabigatran trough plasma concentration required to reduce valve-induced FIla generation should be much higher than $50 \mathrm{ng} / \mathrm{mL}$ (i.e. $260 \mathrm{ng} / \mathrm{mL}$ ) corresponding to a $620-\mathrm{mg}$ bid dosing. ${ }^{69}$ At present, all AF patients with a mechanical valve prosthesis should be treated with VKAs.

\section{Consensus statements:}

\begin{tabular}{|l|l|l|}
\hline $\begin{array}{l}\text { - The use of the oral direct Flla } \\
\text { inhibitor dabigatran in } \\
\text { patients with AF and } \\
\text { mechanical valve prosthesis } \\
\text { is contraindicated. }\end{array}$ & $\begin{array}{l}\text { Coloured } \\
\text { heart }\end{array}$ & $\begin{array}{l}\text { Supporting } \\
\text { references }\end{array}$ \\
\hline - Randomized clinical trials & 7 \\
testing the efficacy and \\
safety of direct oral FXa \\
inhibitors in patients with AF \\
and mechanical heart valve \\
prosthesis are lacking. Until \\
more data are available, \\
rivaroxaban, apixaban and \\
edoxaban are \\
contraindicated in such \\
patients.
\end{tabular}

(Continued) 
(Continued)

\begin{tabular}{|c|c|c|}
\hline & $\begin{array}{l}\text { Coloured } \\
\text { heart }\end{array}$ & $\begin{array}{l}\text { Supporting } \\
\text { references }\end{array}$ \\
\hline $\begin{array}{l}\text { - Until more data are available, } \\
\text { AF patients with any degree } \\
\text { of rheumatic mitral valve } \\
\text { stenosis and those with } \\
\text { moderate-to-severe non- } \\
\text { rheumatic mitral stenosis } \\
\text { should not be treated with } \\
\text { NOACs. }\end{array}$ & & - \\
\hline $\begin{array}{l}\text { The efficacy and safety of } \\
\text { NOACs for stroke/SE } \\
\text { prevention may be similar in } \\
\text { AF patients with and without } \\
\text { conservative valve surgery } \\
\text { such as annuloplasty, } \\
\text { commissurotomy or } \\
\text { valvuloplasty, or } \\
\text { bioprosthetic valves based } \\
\text { on small numbers of patients } \\
\text { in post hoc analyses of RCTs. } \\
\text { More data are needed to } \\
\text { define the role of NOACs in } \\
\text { this setting. }\end{array}$ & & $7,61,70,71$ \\
\hline $\begin{array}{l}\text { - The efficacy and safety of } \\
\text { NOACs in patients with non- } \\
\text { rheumatic mitral and/or } \\
\text { aortic regurgitation or other } \\
\text { native VHD may be similar to } \\
\text { AF patients without VHD } \\
\text { based on small numbers of } \\
\text { patients in post hoc analyses } \\
\text { of RCTs. More data are } \\
\text { needed to define the role of } \\
\text { NOACs in this setting. }\end{array}$ & & $7,22,61,64,72$ \\
\hline $\begin{array}{l}\text { - In patients with } \\
\text { haemodynamically } \\
\text { insignificant valve disease and } \\
\text { in those who have had prior } \\
\text { successful balloon mitral } \\
\text { valvulotomy, NOACs can be } \\
\text { considered as substitute for } \\
\text { VKAs. }\end{array}$ & & $64-69,72$ \\
\hline
\end{tabular}

Note: Consensus statements for TAVI are given in the specific section on TAVI.

\section{Antithrombotic Therapy in Patients with AF Undergoing TAVI or Left Atrial Appendage Occlusion}

\section{Transaortic Valve Intervention Procedure}

Most ischemic events after TAVI are cerebrovascular, and for these AF is a strong contributor. ${ }^{70} \mathrm{AF}$ is common among highrisk patients with severe AS undergoing TAVI, and is associated with a more than twofold increased risk of all-cause and cardiovascular death, irrespective of the type of $\mathrm{AF}^{71}$ In addition, the implanted valve adds a prothrombotic environment, which would accentuate the cardioembolic. Of importance, the gradient of risk directly correlates with the $\mathrm{CHA}_{2} \mathrm{DS}_{2}$-VASc score, which is usually used to aid decision making as whether to initiate $\mathrm{OAC}^{70}$ At least $30 \%$ of the TAVI population deserves
$\mathrm{OAC},{ }^{1}$ a strategy that seems underused and that has never been evaluated prospectively. Dual antiplatelet therapy (DAPT) remains the most widely used antithrombotic strategy after TAVI, being used in $>60 \%$ of patients, while VKA is used in $<20 \%$ of patients, ${ }^{70}$ although AF is observed in $>40 \%$ of TAVI patients. Current recommendations are expert driven, rather than evidence based ( - Table 6 ).

Up to $35 \%$ of patients undergo coronary stenting prior to TAVI. In such patients, the risk of stent thrombosis and/or ischemic cardiac events in addition to that of AF should be considered in the overall risk assessment. ${ }^{73}$ Triple therapy, a combination of a VKA, low-dose aspirin and clopidogrel, which is used in high-risk patients, is associated with an increased risk of death, stroke, TE or major bleeding when compared with VKA alone. ${ }^{71,74}$ Such combinations should be discussed in the context of recent (i.e. $<6$ months) acute coronary syndrome and/or stent implantation, especially in the presence of an unfavourable coronary anatomy (more than three stents, stent length $\geq 60 \mathrm{~mm}$, multivessel disease, left main disease), but should be avoided whenever deemed possible given the established better safety and the possible preserved efficacy of a combination of warfarin and clopidogrel in patients with AF undergoing drug-eluting stent placement. $^{75-77}$

Recent evidence suggests that VKA alone is much safer and provides a similar rate of ischemic events as compared with VKA plus antiplatelet therapy (aspirin) in patients undergoing TAVI. ${ }^{74}$ However, this study was observational, not randomized with an unbalanced number of patients per treatment arm, and randomized confirmation is needed. Therefore, the association of OAC with single antiplatelet therapy in AF patients who underwent successful TAVI should be considered up to 1 year when there is a recent ACS or a recent coronary stenting ${ }^{74}$ and when the bleeding risk is deemed low (-Fig. 2 ).

OAC alone as antithrombotic strategy is currently being tested in three trials (POPular-TAVI NCT02247128, GALILEO NCT02556203, ATLANTIS trial NCT02664649), while another trial is testing aspirin alone or in combination with clopidogrel (ARTE NCT02640794), although AF patients appear excluded. Indeed, the benefit of VKA over DAPT in AF depends on the quality of INR control, ${ }^{78}$ and it has been modelled that a TTR $\geq 58 \%$ would be needed to benefit from being on OAC rather than on DAPT, ${ }^{78}$ which is probably not the case in the TAVI population.

Subclinical valve thrombosis is another challenging issue, as it may occur early after TAVI. Although the frequency of this potentially ominous phenomenon remains undefined, as this condition is difficult to detect, it seems reversible with anticoagulation. Whether it is associated with cerebrovascular events remains to be established. ${ }^{79}$ Given all these uncertainties, ongoing trials are also testing the anticoagulation hypothesis after successful TAVI irrespective of the need for OAC hypotheses using NOACs (NCT02556203, NCT02664649) which have been shown to be better tolerated. - Fig. 2 shows all currently recommended treatment options.

Recent observational evidence suggests the safety of FXa inhibition in TAVI, ${ }^{80}$ showing the feasibility of NOAC in the 
Table 6 Recommendations for antithrombotic therapy during and after TAVI in the guidelines in patients with and without indication for OAC

\begin{tabular}{|c|c|c|c|c|}
\hline & ACC/AHA $/ S_{S T S}^{91}$ & $\mathrm{ESC}^{90}$ & $\mathrm{ACCP}^{40}$ & $\operatorname{CCS}^{40,92}$ \\
\hline Procedural & $\begin{array}{l}\text { Unfractionated } \\
\text { heparin }(\mathrm{ACT}>300 \mathrm{~s})\end{array}$ & - & - & - \\
\hline \multirow[t]{2}{*}{ Post-procedural } & \multirow{2}{*}{$\begin{array}{l}\text { Aspirin } 81 \mathrm{mg} \\
\text { indefinitely and } \\
\text { clopidogrel } 75 \mathrm{mg} \text { for } \\
3 \text { up to } 6 \mathrm{mo}\end{array}$} & $\begin{array}{l}\text { Aspirin (or } \\
\text { clopidogrel) } \\
\text { indefinitely }\end{array}$ & \multirow[t]{2}{*}{$\begin{array}{l}\text { Aspirin }(50-100 \mathrm{mg} / \mathrm{d}) \\
\text { and clopidogrel }(75 \\
\mathrm{mg} / \mathrm{d}) \text { in the first } 3 \mathrm{mo}\end{array}$} & \multirow{2}{*}{$\begin{array}{l}\text { Low-dose aspirin } \\
\text { indefinitely and } 1-3 \\
\text { mo of a thienopyridine } \\
\text { (no evidence) }\end{array}$} \\
\hline & & $\begin{array}{l}\text { Aspirin and } \\
\text { clopidogrel in the first } \\
3 \text { mo after TAVI }\end{array}$ & & \\
\hline $\begin{array}{l}\text { Patients with a clear } \\
\text { indication for OAC (as } \\
\text { in AF) }\end{array}$ & $\begin{array}{l}\text { It is reasonable to } \\
\text { continue low-dose } \\
\text { aspirin, but other } \\
\text { antiplatelet therapy } \\
\text { should be avoided }\end{array}$ & $\begin{array}{l}\text { No antiplatelet } \\
\text { therapy but OAC alone }\end{array}$ & No recommendation & $\begin{array}{l}\text { Adjunctive antiplatelet } \\
\text { agents are } \\
\text { controversial and } \\
\text { triple therapy should } \\
\text { be avoided }\end{array}$ \\
\hline
\end{tabular}

Abbreviations: ACC, American College of Cardiology; ACT, activated clotting time; ACCP, American College of Chest Physicians; AF, atrial fibrillation; AHA, American Heart Association; ASA, acetylsalicylic acid (aspirin); AVR, aortic valve replacement; CCS, Canadian Cardiovascular Society; ESC, European Society of Cardiology; INR, international normalized ratio; OAC, oral anticoagulation; VKA, vitamin K antagonists.

post-TAVI setting. However, results from randomized comparison of FXa inhibition versus other antithrombotic strategies are lacking.

\section{Left Atrial Appendage Occlusion Procedure}

Following clinical trials, ${ }^{81-83}$ percutaneous endovascular left atrial appendage occlusion (LAAO) has been increasingly developed and performed worldwide for patients with $\mathrm{AF}$, especially those with contraindications to long-term OAC. ${ }^{84}$ This is supported by guidelines from the ESC, which give a class IIB recommendation for LAAO in AF patients with high stroke risk and contraindications to long-term OAC. ${ }^{2}$
Antithrombotic therapy following LAAO has not been well evaluated, and it is not even known whether OAC or antiplatelet therapy or no therapy is preferable. When possible, according to the patient bleeding risk profile, after LAAO most centres use a 6-week period of VKA (target INR: 2.5 ) followed by once daily (od) clopidogrel $(75 \mathrm{mg}$ ) and aspirin (75-325 mg) until the 6-month visit. Some patients may also receive NOAC. ${ }^{85}$ Subsequently, low-dose aspirin alone is continued indefinitely, as tested in the pivotal trials. ${ }^{81,82,86}$ This antiplatelet regimen has never been compared with any long-term NOAC-based OAC regimen. ${ }^{87,88}$ However, the ASAP study showed that LAAO with the Watchman device

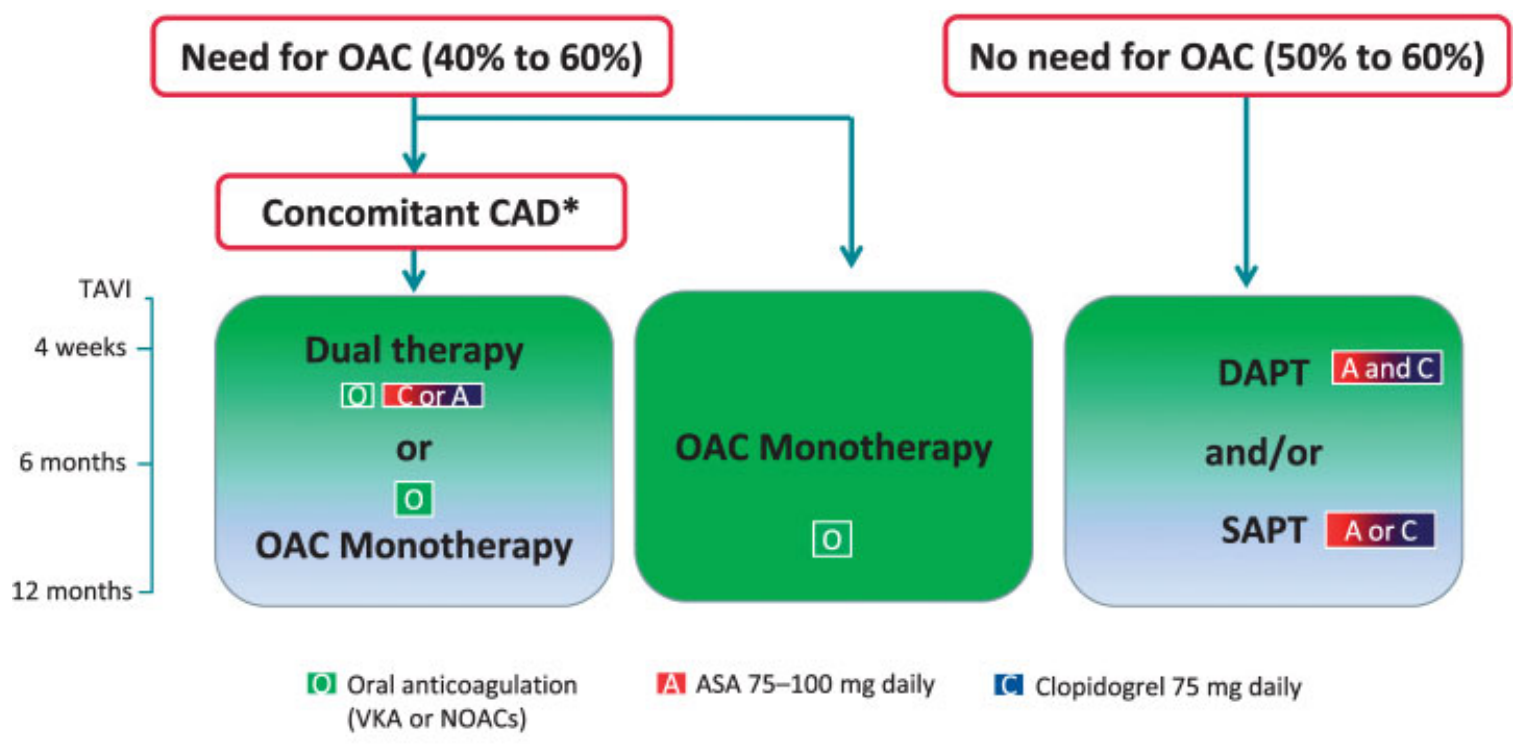

*Recent ACS or coronary stenting ( $<6$ months)

Fig. 2 Proposed algorithm for AF patients undergoing a TAVI procedure. (Adapted Gargiulo et al ${ }^{130}$ ). O refers to oral anticoagulation as VKA (or possibly NOAC). ACS, acute coronary syndrome; AF, atrial fibrillation; CAD, coronary artery disease; DAPT, dual antiplatelet therapy; OAC, NOAC, non-vitamin K antagonist oral anticoagulant; oral anticoagulant; SAPT, single antiplatelet therapy; TAVI, transaortic valve intervention; VKA, vitamin $\mathrm{K}$ antagonist. 
is feasible and could be safely performed without OAC cover (but with antiplatelet therapy). ${ }^{86}$ Such strategy is being evaluated in the ongoing ADRIATIC study (Apixaban versus Dual or single antiplatelet therapy to Reduce Ischemic and bleeding events in Atrial fibrillation patients Treated with Invasive Closure of the left atrial appendage).

The ASAP TOO randomized trial (NCT02928497) is currently establishing the safety and effectiveness of the LAAO versus single antiplatelet therapy in patients with nonvalvular AF deemed not to be eligible for OAC to reduce the risk of stroke.

\section{Consensus statements:}

\begin{tabular}{|c|c|c|}
\hline & $\begin{array}{l}\text { Coloured } \\
\text { heart }\end{array}$ & $\begin{array}{l}\text { Supporting } \\
\text { references }\end{array}$ \\
\hline $\begin{array}{l}\text { - AF patients who underwent } \\
\text { successful TAVI may be } \\
\text { treated with NOACs; } \\
\text { however, data are limited. }\end{array}$ & & 89 \\
\hline $\begin{array}{l}\text { - AF patients with stable } \\
\text { coronary artery disease who } \\
\text { underwent TAVI may be } \\
\text { treated with OAC only, } \\
\text { including VKA and FXa } \\
\text { inhibitors; however, } \\
\text { prospective data are limited. }\end{array}$ & & $74,89-92$ \\
\hline $\begin{array}{l}\text { - Based on trial protocols, OAC } \\
\text { and single antiplatelet } \\
\text { therapy after successful } \\
\text { LAAO may be used up to } \\
6 \text { weeks in low bleeding risk } \\
\text { patients, followed by single } \\
\text { antiplatelet therapy; } \\
\text { however, long-term data are } \\
\text { limited, nor any comparison } \\
\text { with NOACs. }\end{array}$ & & $81,82,86$ \\
\hline $\begin{array}{l}\text { - Single antiplatelet therapy or } \\
\text { no antithrombotic therapy } \\
\text { may be used after LAAO in AF } \\
\text { patients who are not eligible } \\
\text { for VKA; however, long-term } \\
\text { data are limited, nor any } \\
\text { comparison with NOACs. }\end{array}$ & & 87,88 \\
\hline
\end{tabular}

\section{Antithrombotic Therapy for Valvular AF in Pregnant Women}

Valvular AF in pregnancy is relatively rare and can be due to congenital heart disease, mitral valve prolapse with significant MR, or to rheumatic heart disease. Valves can be repaired or replaced with a mechanical valve prosthesis. ${ }^{93}$ Pregnancy by itself is a prothrombotic state and the coalescence of venous stasis and hypercoagulability results in nearly a fivefold increase in the risk of venous TE during pregnancy. ${ }^{94}$ The goal of anticoagulation during pregnancy should be to safely balance the maternal risk of TE and haemorrhage with the foetal risk of exposure to VKA. The continuously changing pharmacokinetics of low-molecular- weight heparin during the various trimesters adds an additional challenge and requires monitoring by peak and trough anti-Xa levels, ${ }^{94}$ which is often not feasible (-Fig. 3).

Women of child-bearing age with VHD need to be comprehensively counselled prior to valve replacement and prepregnancy to decide on the most appropriate type of valve and to be made aware of the teratogenicity and fetotoxicity of VKA, pregnancy-induced hemodynamic changes and the pre-existing hypercoagulable state which can compromise foetal development and significantly increase the risk of serious and/or fatal complications to both mother and child. ${ }^{95}$ Women with mechanical prosthetic valves should ideally have preconception evaluation, including advice on risk prediction and contraception, by a joint cardiacobstetric team seeking advice from other specialties. ${ }^{93}$ Careful counselling on maternal and offspring risk should be done according to the modified World Health Organization classification and should include information on complications such as heart failure, valve thrombosis and bleeding complications which can occur during or beyond the immediate delivery period. Also, the consequences of the medication that may be required (e.g. warfarin embryopathy) need to be discussed. However, often women in some countries may present after 20 weeks of gestation, which has implications for their functional assessment, harmful medication cannot be terminated timely and limits the option for pregnancy termination.

Since anticoagulation is recommended in pregnant patients with $\mathrm{AF}$ at risk of stroke, to minimize teratogenic risk and intrauterine bleeding, the ESC guidelines recommend that dose-adjusted heparin should be used during the first trimester of pregnancy and in the 2 to 4 weeks before delivery. ${ }^{2}$ VKA or heparin can be used in the remaining trimesters of the pregnancy. ${ }^{2}$ In the absence of adequate safety data, NOACs should clearly be avoided in pregnancy and in women planning a pregnancy. ${ }^{2}$

Consensus statements:

\begin{tabular}{|c|c|c|}
\hline & $\begin{array}{l}\text { Coloured } \\
\text { heart }\end{array}$ & $\begin{array}{l}\text { Supporting } \\
\text { references }\end{array}$ \\
\hline $\begin{array}{l}\text { - There is no consensus on the } \\
\text { optimal regimen for } \\
\text { anticoagulation in } \\
\text { peripartum women with } \\
\text { mechanical valve prosthesis } \\
\text { with AF. }\end{array}$ & & $93,94,96$ \\
\hline $\begin{array}{l}\text { - As the optimal } \\
\text { anticoagulation regimen for } \\
\text { use in pregnancy and } \\
\text { peripartum remains } \\
\text { undetermined, all decisions } \\
\text { should be made by a fully } \\
\text { informed mother and } \\
\text { partner in consultation with } \\
\text { a multidisciplinary team. }\end{array}$ & & $93,94,96$ \\
\hline
\end{tabular}




\section{Management Strategies for women with mechanical valve prosthesis}

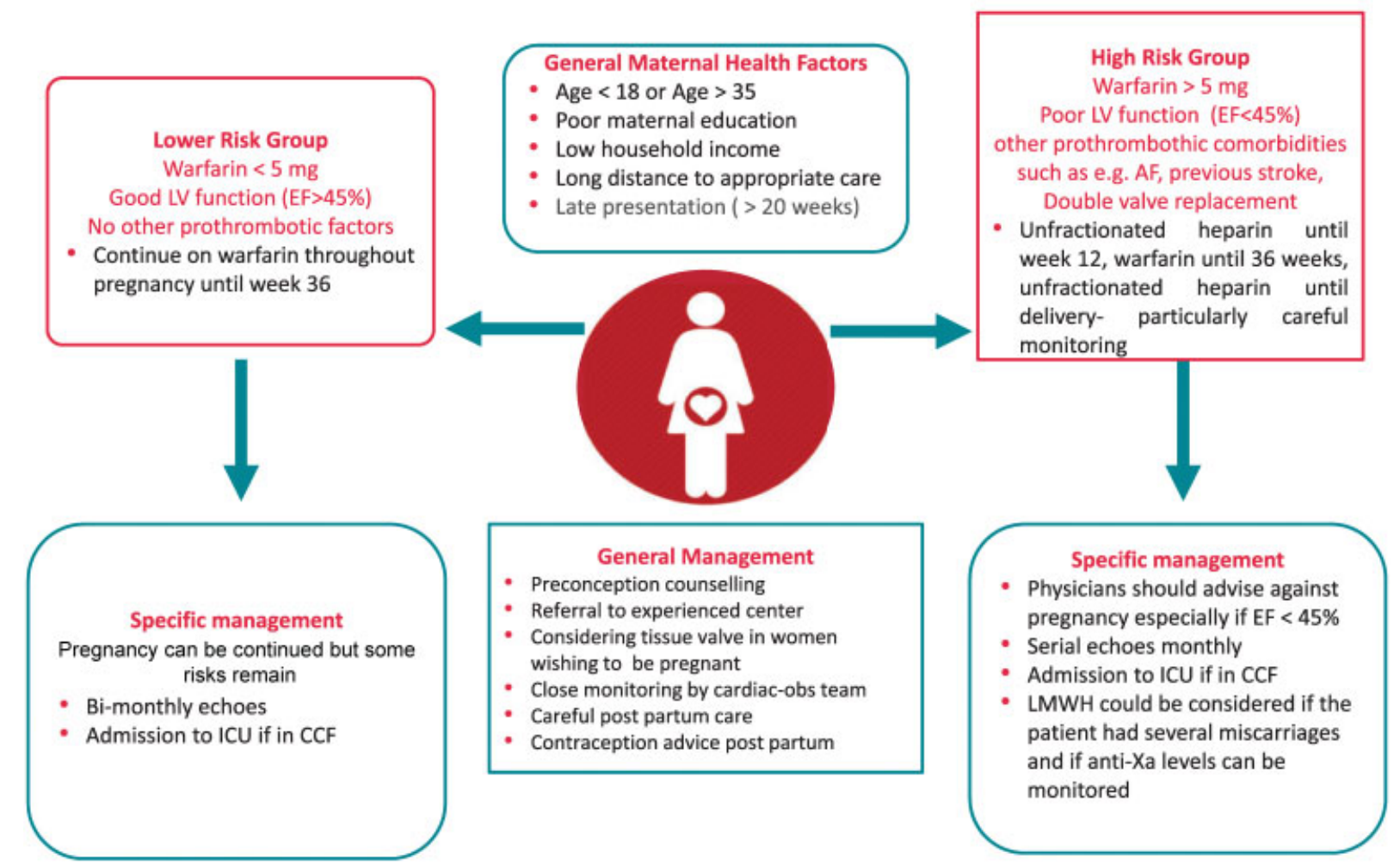

Fig. 3 Management strategies for women with mechanical valve prosthesis. CCF, congestive heart failure; ICU, intensive care unit.

\section{Patient Values and Preferences, and Societal Issues}

Treatment decisions need to balance the benefits and risks of treatment and manage realistic patient expectations, particularly in association with comorbidities and in pregnancy. These decisions are complex and require assimilation of life expectancy, ability and willingness to take anticoagulants, risk of bleeding, lifestyle, comorbidities, risk of reoperation and patient preference. ${ }^{97-99}$

Clinical guidelines on the management of $\mathrm{VHD}^{97}$ advocate incorporating informed patient preferences into treatment decisions and technological advances (for VHD) must be employed 'responsibly within a framework of care which enables shared decision making and promotes patient goals and wellbeing. ${ }^{100}$ This requires candid discussions between the patient and physician to ensure that treatment is not futile. Shared decision making ${ }^{100,101}$ requires patients to be appropriately informed about treatment options and likely outcomes, to have the type of patient-physician relationship where patients feel able to ask questions and where physicians provide information and communicate risk effectively, ${ }^{102,103}$ to enable patients to make an informed decision incorporating their values, goals and preferences. ${ }^{100,104,105}$ Patient's treatment preferences are likely to vary markedly, with patients often willing to accept higher levels of risk. ${ }^{105}$ Patient decision aids including microsimulation models are available for patients with VHD. ${ }^{106,107}$

\section{Implications for Low-to-Middle Income Countries}

Valvular AF is more common in the Asian and African population compared with their western counterparts mainly due to greater burden of rheumatic heart disease. ${ }^{108-110}$ Stroke risk is higher among patients with valvular AF (17-18\%/year) compared with those with non-valvular AF (4\%/year). ${ }^{111}$ Furthermore, AF may further increase the risk of bioprosthetic valve thrombosis (-Supplementary Table S4 [online only]). ${ }^{112}$ The burden of rheumatic valve disease is higher, but the quality of anticoagulation is suboptimal in low- and middle-income countries. Monitoring of the INR and follow-up remains poor and significant proportion of patients presents with subtherapeutic INR. The majority of these patients are young (median age: 28 years), ${ }^{110}$ unemployed $(75.3 \%)$ and women $(51-66 \%)^{110,113}$ of reproductive age. On average, they tend to be nearly 10 to 12 years younger than their western counterparts.

Many are unaware of the concept of therapeutic range INR (60\%) and few $(<4 \%)$ are on contraceptives despite treatment with warfarin. The NOACs are expensive and beyond the reach of the majority of patients requiring them in these countries. Suboptimal anticoagulation and consequent increased risk of stroke may lead to significant disability-adjusted life-years lost and this is likely to pose a major economic burden.

Strategies to improve awareness about the disease, medication side effects, the importance of medication adherence and INR monitoring, and the danger of anticoagulation during pregnancy are scanty. Although point-of-care INR testing shows promise (-Supplementary Table S4 [Online only]), 
its use among patients from the developing world needs to be determined. The impact of NOACs is less certain, although one recent Brazilian study evaluating NOACs in public health system context found that NOACs present a lower cumulative cost per patient when compared with VKAs. ${ }^{14}$

\section{Health Economic Perspectives}

$\mathrm{AF}$ is a disease that induces significant consumption of resources and costs, encompassing direct medical costs, associated with patient's medical care (hospitalizations, medications, outpatient visits, etc.), and direct non-medical costs (i.e. costs related to residential or social care, as well as out-of-pocket expenses). ${ }^{115,116}$

Other costs that are usually taken into account in healtheconomic analyses are productivity losses caused by patients' inability to work, or absence from work of relatives providing informal care. ${ }^{115}$ In patients with $\mathrm{AF}$, direct costs, reported as per-patient annual costs, have been estimated to be $\$ 2,000$ to 14,200 in North America and 450 to 3,000 Euros in Europe per patient. ${ }^{117}$

Patients with VHD who have AF require appropriate risk stratification for stroke/SE and, when indicated, the consequent prescription of OAC implies a difficult balance between the risk of stroke and systemic TE and the risk of bleeding. ${ }^{118,119}$ Stroke and major bleeding have also an economic effect. Indeed, the main drivers of costs in AF patients are AFrelated hospitalizations, stroke and haemorrhagic events. For strokes occurring in patients with $\mathrm{AF}$, the direct costs per patient are approximately $33 \%$ greater than the costs of stroke not related to $\mathrm{AF}^{120}$ and are in the range of 30,000 Euros over a 2-year period for a severe ischemic stroke. ${ }^{121}$ The costs of intracerebral haemorrhage is $50 \%$ higher than the cost of ischemic stroke over a 1 -year time course. ${ }^{122}$

Underutilization of, and non-adherence to, warfarin is also quite common and is associated with increased costs, ${ }^{123,124}$ resulting from TE and haemorrhagic complications. Improved adherence to OAC in AF patients at risk of stroke is important to attain the full clinical and economic benefit of thromboprophylaxis.

NOACs can be prescribed to some subgroups of patients with $\mathrm{VHD}^{4,125,126}$ and a series of analyses focusing on the costeffectiveness of these agents versus warfarin has been published, although no study considered patients with VHD separately. In general, despite the higher cost of NOACs as compared with warfarin, the associated benefits make these agents cost-effective in the long term, especially in settings with poor anticoagulation control associated with VKAs. ${ }^{127,128}$

\section{Consensus statements:}

\begin{tabular}{|c|c|c|}
\hline & $\begin{array}{l}\text { Coloured } \\
\text { heart }\end{array}$ & $\begin{array}{l}\text { Supporting } \\
\text { references }\end{array}$ \\
\hline $\begin{array}{l}\text { - Appropriate use of oral } \\
\text { anticoagulants, when clinically } \\
\text { indicated, has both a clinical and } \\
\text { economic value, as } \\
\text { underutilization and/or } \\
\text { non-adherence are associated } \\
\text { with adverse outcomes and } \\
\text { increased costs. }\end{array}$ & & $7119-121$ \\
\hline
\end{tabular}

\section{Summary and Areas for Future Research}

\section{Mechanical Valve Prostheses}

Currently, patients with AFand a mechanical prosthesis should only be treated with a VKA. Since the RE-ALIGN study, no other NOAC (FXa inhibitor drug class) has been tested in this patient group. ${ }^{68}$ However, the thrombotic risk could be reduced once endothelial tissue is present around the ring. ${ }^{12}$ A RCT could potentially be designed after endothelialization: the first 3 months with VKA, followed by a randomized comparison between continuing VKA or switching to a NOAC.

One trial proposed or ongoing with NOACs in patients with and without AF is the CATHAR trial (Comparison of Antithrombotic Treatments after Aortic Valve Replacement; Rivaroxaban: A New Antithrombotic Treatment for Patients with Mechanical Prosthetic Aortic Heart Valve: https://clinicaltrials.gov/ct2/show/NCT02128841?

term=rivaroxaban + and + mechanical + valve $\&$ rank $=2$ ).

\section{Bioprostheses, TAVI and TMVI}

Usually, patients with a bioprosthesis and AF receive a VKA. Pericardial valves are less thrombogenic than mechanical valve prostheses. Some physicians do not consider bioprostheses as a contra-indication of NOACs. Before recommending a NOAC rather than VKA for these patients, a RCT is needed. This is also the case for patients undergoing valve repair.

TAVI corresponds to transluminal implantation of a bioprosthesis and is being increasingly used. The antithrombotic treatment in patients with sinus rhythm and TAVI remains controversial and the optimal treatment in patients with AF requiring TAVI (as well as TMVI-see earlier section) is currently unknown.

A global study comparing a rivaroxaban-based antithrombotic strategy to an antiplatelet-based strategy after TAVI to optimize clinical outcomes (GALILEO) is ongoing. ${ }^{129,130}$ The two arms consist of either rivaroxaban $10 \mathrm{mg}$ od plus aspirin 75 to $100 \mathrm{mg}$ for the first 90 days, followed by rivaroxaban alone; or clopidogrel $75 \mathrm{mg}$ plus aspirin 75 to $100 \mathrm{mg}$ for the first 90 days, followed by clopidogrel alone. Patients with current or previous AF are excluded. The investigators assume that $15 \%$ of patients in sinus rhythm at inclusion will develop AF during follow-up. Treatment after new-onset AF will be, in patients randomized to rivaroxaban, a switch to rivaroxaban 20 or $15 \mathrm{mg}$ od for those with moderate renal impairment and in those randomized to clopidogrel, a switch to VKA (target INR: 2-3).

Another ongoing study is the Anti-Thrombotic Strategy after Trans-Aortic Valve Implantation for Aortic Stenosis (ATLANTIS) study which is ongoing and plans to include 1,509 patients after successful TAVI procedure. Randomization will be stratified according to the need for oral anticoagulant. Patients with an indication for OAC will be randomized 1:1 to VKA or apixaban $5 \mathrm{mg}$ bid. The primary endpoint after 1 year follow-up is a composite of death, myocardial infarction, stroke, systemic embolization, intracardiac or bioprosthesis thrombus, episode of deep vein thrombosis or pulmonary embolism, and major bleeding. Patients with no indication for oral anticoagulant therapy will be randomized 1:1 to either apixaban $5 \mathrm{mg}$ bid or 
antiplatelet therapy. Other trials are also proposed or ongoing with NOACs in patients with and without AF, including the RIVER Trial (RIvaroxaban for bioprosthetic Valvular Heart diseasE and atRial Fibrillation Trial; warfarin vs. rivaroxaban).

\section{Native Valve Diseases}

The main phase III studies of NOACs have used variable criteria for excluding valvular patients. Some studies (ROCKET-AF and ARISTOTLE) excluded only patients with mechanical valve prostheses and significant (moderate to severe) MS. The subanalyses did not show any differences in efficacy among patients with and without VHD. In the ROCKET-AF, there was more bleeding on rivaroxaban than on VKA in patients with VHD.

A report from the Loire Valley Atrial Fibrillation Project compared the outcome of patients without any valve disease and those with valve disease but did not include either valve prosthesis or MS. Although patients with VHD had a higher risk of stroke and TE events on univariable analysis, the difference was no longer significant after adjustment, in line with an older age and a higher $\mathrm{CHA}_{2} \mathrm{DS}_{2}$-VASC score in patients with VHD. ${ }^{126}$

However, post hoc analyses are only hypothesis generating. Large RCTs are needed with NOACs in the setting of AS, non-rheumatic AR and MR before the role of NOACs can be fully defined in this setting.

\section{Mitral Stenosis}

There has not yet been a RCT comparing VKA and NOACs in these patients. The prevalence of rheumatic MS has become low in Western countries but remains high in Eastern Europe, India, Africa, South America and South East Asia. In these regions, the TTR is only 35 to $44 \%$, according to a global AF registry. ${ }^{5}$ RCTs comparing VKA with a NOAC are highly welcomed and should preferably include patients from these affected countries.

\section{Acknowledgements}

This article is an Executive Summary of the full consensus document which has been published as Lip et al Europace 2017; 19, 1757-1758

\section{Document Reviewers}

Bulent Gorenek (reviewer coordinator): Eskisehir Osmangazi University, Eskisehir, Turkey

Irina Savelieva: Molecular and Clinical Sciences Institute, St George's University of London, London, United Kingdom Christian Sticherling: Department of Cardiology, University Hospital Basel, Basel, Switzerland

Gulmira Kudaiberdieva: Adana, Turkey

Tze-Fan Chao (APHRS reviewer): Division of Cardiology, Department of Medicine, Taipei Veterans General Hospital, and Institute of Clinical Medicine, Cardiovascular Research Center, National Yang-Ming University, Taipei, Taiwan Francesco Violi: University of Rome La Sapienza, Rome, Italy Mohan Nair: Department of Cardiology, Max Super Specialty Hospital, New Delhi, India

Leandro Zimerman (SOLAECE reviewer): Hospital de Clínicas de Porto Alegre, Federal University of Rio Grande do Sul, Porto Alegre, Brazil
Jonathan Piccini (HRS reviewer): Duke Clinical Research Institute, Duke University Medical Center, Durham, North Carolina, United States

Robert Storey: Department of Cardiovascular Sciences, University of Sheffield, Sheffield, United Kingdom

Sigrun Halvorsen: National Heart and Lung Institute, Imperial College, London, and Postgraduate Medicine, University of Hertfordshire, Hertfordshire, United Kingdom

Diana Gorog: Department of Cardiology, Oslo University Hospital, Ulleval, Oslo, Norway

Andrea Rubboli (Working Group of Thrombosis reviewer): Ospedale Maggiore - Division of Cardiology, Bologna, Italy Ashley Chin (CASSA reviewer): Electrophysiology and Pacing, Groote Schuur Hospital, University of Cape Town, South Africa

Robert Scott-Millar (SAHeart reviewer): Division of Cardiology, Department of Medicine, University of Cape Town, South Africa.

\section{Task Force members and affiliations}

\begin{tabular}{|c|c|}
\hline From EHRA: & \\
\hline $\begin{array}{l}\text { Gregory Y. H. Lip (Chair) } \\
\text { (UK, representing EHRA) }\end{array}$ & $\begin{array}{l}\text { Institute of Cardiovascular Sciences, } \\
\text { University of Birmingham, United } \\
\text { Kingdom; and Aalborg Thrombosis } \\
\text { Research Unit, Department of Clinical } \\
\text { Medicine, Aalborg University, Aalborg, } \\
\text { Denmark }\end{array}$ \\
\hline Laurent Fauchier & $\begin{array}{l}\text { Centre Hospitalier Universitaire } \\
\text { Trousseau et Faculté de Médecine - } \\
\text { Université François Rabelais, Tours, } \\
\text { France }\end{array}$ \\
\hline Raffaele De Caterina & $\begin{array}{l}\text { Institute of Cardiology, 'G. d'Annunzio' } \\
\text { University, Chieti, Italy }\end{array}$ \\
\hline Deirdre A. Lane & $\begin{array}{l}\text { Institute of Cardiovascular Sciences, } \\
\text { University of Birmingham, United } \\
\text { Kingdom; and Aalborg Thrombosis } \\
\text { Research Unit, Department of Clinical } \\
\text { Medicine, Aalborg University, Aalborg, } \\
\text { Denmark }\end{array}$ \\
\hline Torben B. Larsen & $\begin{array}{l}\text { Aalborg Thrombosis Research Unit, } \\
\text { Department of Clinical Medicine, } \\
\text { Aalborg University, Aalborg, Denmark }\end{array}$ \\
\hline Francisco Marin & $\begin{array}{l}\text { Department of Cardiology, Hospital } \\
\text { Universitario Virgen de la Arrixaca, } \\
\text { Murcia, Spain }\end{array}$ \\
\hline Tatjana Potpara & $\begin{array}{l}\text { School of Medicine, Belgrade } \\
\text { University; Cardiology Clinic, Clinical } \\
\text { Centre of Serbia, Belgrade, Serbia }\end{array}$ \\
\hline Nizal Sarrafzadegan & $\begin{array}{l}\text { Isfahan cardiovascular Research Center } \\
\text { (WHO Collaborating Center), } \\
\text { Cardiovascular Research Institute, } \\
\text { Isfahan University of Medical Sciences, } \\
\text { Isfahan, Iran; and School of Population } \\
\text { and Public Health, University of British } \\
\text { Columbia, Vancouver, Canada }\end{array}$ \\
\hline \multicolumn{2}{|l|}{ From WG on Thrombosis } \\
\hline $\begin{array}{l}\text { Bianca Rocca } \\
\text { (Co-Chair) (Italy) }\end{array}$ & $\begin{array}{l}\text { Department of Pharmacology, } \\
\text { Catholic University School of Medicine, } \\
\text { Rome, Italy }\end{array}$ \\
\hline Jean Philippe Collet & $\begin{array}{l}\text { ACTION Study Group (www.action- } \\
\text { coeur.org), Institut de Cardiologie } \\
\text { Hôpital Pitié-Salpêtrière (APHP), } \\
\text { Sorbonne Université Paris 6, INSERM } \\
\text { UMRS } 1166 \text { Paris, France }\end{array}$ \\
\hline
\end{tabular}

(Continued) 
(Continued)

\begin{tabular}{|c|c|}
\hline Joao Morais & $\begin{array}{l}\text { Department of Cardiology, Leiria } \\
\text { Hospital Centre, Portugal }\end{array}$ \\
\hline Gemma Vilahur & $\begin{array}{l}\text { Cardiovascular Research Center (CSIC- } \\
\text { ICCC), IIB-HSCSP, Barcelona, Spain }\end{array}$ \\
\hline Thomas W. Weiss & $\begin{array}{l}\text { 3rd Medical Department for } \\
\text { Cardiology and Intensive Care, } \\
\text { Wilhelminenhospital, Vienna, Austria; } \\
\text { and Medical Faculty, Sigmund Freud } \\
\text { University, Vienna, Austria }\end{array}$ \\
\hline \multicolumn{2}{|l|}{ HRS representative } \\
\hline Brian Olshansky & $\begin{array}{l}\text { Clinical Cardiac Electrophysiology, } \\
\text { Cardiology Mercy Hospital, Mason } \\
\text { City, lowa, United States }\end{array}$ \\
\hline \multicolumn{2}{|l|}{ APHRS representative } \\
\hline C. Narasimhan & $\begin{array}{l}\text { Department of Cardiac } \\
\text { Electrophysiology, CARE Hospital, } \\
\text { Hyderabad, India }\end{array}$ \\
\hline \multicolumn{2}{|l|}{ SOLEACE representative } \\
\hline Gonzalo Varela & $\begin{array}{l}\text { Servicio de Electrofisiología, Centro } \\
\text { Cardiovascular Casa de Galicia, } \\
\text { Uruguay }\end{array}$ \\
\hline \multicolumn{2}{|l|}{ SAHeart representative } \\
\hline Karen Sliwa & $\begin{array}{l}\text { Hatter Institute for Cardiovascular } \\
\text { Research in Africa, IDM, Faculty of } \\
\text { Health Sciences, University of Cape } \\
\text { Town, South Africa }\end{array}$ \\
\hline \multicolumn{2}{|l|}{$\begin{array}{l}\text { WG Valvular Heart } \\
\text { Disease representative }\end{array}$} \\
\hline Luc A. PIERARD (Head) & $\begin{array}{l}\text { Department of Cardiology, University } \\
\text { Hospital Sart-Tilman, Belgium }\end{array}$ \\
\hline \multicolumn{2}{|l|}{ Health economic perspective } \\
\hline Giuseppe Boriani & $\begin{array}{l}\text { University of Modena and Reggio Emilia, } \\
\text { Policlinico di Modena, Modena, Italy }\end{array}$ \\
\hline
\end{tabular}

\section{References}

1 Molteni M, Polo Friz H, Primitz L, Marano G, Boracchi P, Cimminiello $C$. The definition of valvular and non-valvular atrial fibrillation: results of a physicians' survey. Europace 2014;16 (12):1720-1725

2 Kirchhof P, Benussi S, Kotecha D, et al. 2016 ESC Guidelines for the management of atrial fibrillation developed in collaboration with EACTS The Task Force for the management of atrial fibrillation of the European Society of Cardiology (ESC) Developed with the special contribution of the European Heart Rhythm Association (EHRA) of the ESC Endorsed by the European Stroke Organisation (ESO). Eur Heart J 2016; 37:2893-2962

3 De Caterina R, John Camm A. Non-vitamin K antagonist oral anticoagulants in atrial fibrillation accompanying mitral stenosis: the concept for a trial. Europace 2016;18(01):6-11

4 De Caterina R, Camm AJ. What is 'valvular' atrial fibrillation? A reappraisal. Eur Heart J 2014;35(47):3328-3335

5 Oldgren J, Healey JS, Ezekowitz M, et al; RE-LY Atrial Fibrillation Registry Investigators. Variations in cause and management of atrial fibrillation in a prospective registry of 15,400 emergency department patients in 46 countries: the RE-LY Atrial Fibrillation Registry. Circulation 2014;129(15):1568-1576

6 Fukuda N, Hirai T, Ohara K, Nakagawa K, Nozawa T, Inoue H. Relation of the severity of mitral regurgitation to thromboembolic risk in patients with atrial fibrillation. Int J Cardiol 2011; 146(02):197-201
7 Heidbuchel H, Verhamme P, Alings M, et al. Updated European Heart Rhythm Association Practical Guide on the use of nonvitamin $\mathrm{K}$ antagonist anticoagulants in patients with non-valvular atrial fibrillation. Europace 2015;17(10):1467-1507

8 Petronio AS, Capranzano P, Barbato E, et al. Current status of transcatheter mitral valve therapy in Europe: results from an EAPCI survey (Part II). EuroIntervention 2017;12(16): 1934-1939

9 Molteni M, Polo Friz H, Primitz L, Marano G, Boracchi P, Cimminiello C. The definition of valvular and non-valvular atrial fibrillation: results of a physicians' survey. Europace 2014;16 (12):1720-1725

10 Elliott PM, Anastasakis A, Borger MA, et al; Authors/Task Force Members. 2014 ESC Guidelines on diagnosis and management of hypertrophic cardiomyopathy: the Task Force for the Diagnosis and Management of Hypertrophic Cardiomyopathy of the European Society of Cardiology (ESC). Eur Heart J 2014;35(39): 2733-2779

11 Benhorin J, Bodenheimer M, Brown M, et al; Multicenter Cardiac Research Group. Improving clinical practice guidelines for practicing cardiologists. Am J Cardiol 2015;115(12):1773-1776

12 De Caterina R, Husted S, Wallentin L, et al; Coordinating Committee. New oral anticoagulants in atrial fibrillation and acute coronary syndromes: ESC Working Group on Thrombosis-Task Force on Anticoagulants in Heart Disease position paper. J Am Coll Cardiol 2012;59(16):1413-1425

13 Watson T, Shantsila E, Lip GY. Mechanisms of thrombogenesis in atrial fibrillation: Virchow's triad revisited. Lancet 2009;373 (9658):155-166

14 Goette A, Kalman JM, Aguinaga L, et al; Document Reviewers: Osmar A. Centurion (Paraguay), Karl-Heinz Kuck (Germany), Kristen K. Patton (USA), John L. Sapp (Canada), Martin Stiles (New Zealand), Jesper Hastrup Svendsen (Denmark), and Gaurav A. Upadhyay (USA); Review coordinator: Alena Shantsila (UK). EHRA/HRS/APHRS/SOLAECE expert consensus on Atrial cardiomyopathies: Definition, characterisation, and clinical implication. J Arrhythm 2016;32(04):247-278

15 Baumgartner H, Hung J, Bermejo J, et al; American Society of Echocardiography; European Association of Echocardiography. Echocardiographic assessment of valve stenosis: EAE/ASE recommendations for clinical practice. J Am Soc Echocardiogr 2009;22(01):1-23, quiz 101-102

16 Fauchier L, Philippart R, Clementy N, et al. How to define valvular atrial fibrillation? Arch Cardiovasc Dis 2015;108(10):530-539

17 Dewanjee MK, Gross DR, Zhai P, et al. Thrombogenicity of polyethylene oxide-bonded Dacron sewing ring in a mechanical heart valve. J Heart Valve Dis 1999;8(03):324-330

18 Natorska J, Mazur P, Undas A. Increased bleeding risk in patients with aortic valvular stenosis: from new mechanisms to new therapies. Thromb Res 2016;139:85-89

19 Vahanian A, Alfieri O, Andreotti F, et al; Joint Task Force on the Management of Valvular Heart Disease of the European Society of Cardiology (ESC); European Association for CardioThoracic Surgery (EACTS). Guidelines on the management of valvular heart disease (version 2012). Eur Heart J 2012;33(19): 2451-2496

20 Vahanian A, Alfieri O, Andreotti F, et al; Joint Task Force on the Management of Valvular Heart Disease of the European Society of Cardiology (ESC); European Association for Cardio-Thoracic Surgery (EACTS). Guidelines on the management of valvular heart disease (version 2012). Eur Heart J 2012;33(19): 2451-2496

21 Heidbuchel $\mathrm{H}$, Verhamme P, Alings M, et al. Updated European Heart Rhythm Association Practical Guide on the use of nonvitamin $\mathrm{K}$ antagonist anticoagulants in patients with non-valvular atrial fibrillation. Europace 2015;17(10):1467-1507

22 Carnicelli AP, De Caterina R, Halperin JL, et al; ENGAGE AF-TIMI 48 Investigators. Edoxaban for the prevention of thromboembolism 
in patients with atrial fibrillation and bioprosthetic valves. Circulation 2017;135(13):1273-1275

23 Renda R, De Caterina R, Carnicelli A, et al. Outcomes in 2824 patients with valvular heart disease treated with edoxaban or warfarin in the ENGAGE AF-TIMI 48 trial. J Am Coll Cardiol 2016; 67(01):2194

24 De Caterina R, Renda G, Carnicelli AP, et al. Valvular heart disease patients on edoxaban or warfarin in the ENGAGE AF-TIMI 48 trial. J Am Coll Cardiol 2017;69(11):1372-1382

25 Salem DN, O'Gara PT, Madias C, Pauker SG. Valvular and structural heart disease: American College of Chest Physicians Evidence-Based Clinical Practice Guidelines (8th Edition). Chest 2008;133(6, Suppl):593S-629S

26 Heras M, Chesebro JH, Fuster V, et al. High risk of thromboemboli early after bioprosthetic cardiac valve replacement. J Am Coll Cardiol 1995;25(05):1111-1119

27 Mérie C, Køber L, Skov Olsen P, et al. Association of warfarin therapy duration after bioprosthetic aortic valve replacement with risk of mortality, thromboembolic complications, and bleeding. JAMA 2012;308(20):2118-2125

28 January CT, Wann LS, Alpert JS, et al; American College of Cardiology/American Heart Association Task Force on Practice Guidelines. 2014 AHA/ACC/HRS guideline for the management of patients with atrial fibrillation: a report of the American College of Cardiology/ American Heart Association Task Force on Practice Guidelines and the Heart Rhythm Society. J Am Coll Cardiol 2014;64(21):e1-e76

29 Aramendi JI, Mestres C-A, Martinez-León J, Campos V, Muñoz G, Navas C. Triflusal versus oral anticoagulation for primary prevention of thromboembolism after bioprosthetic valve replacement (trac): prospective, randomized, co-operative trial. Eur J Cardiothorac Surg 2005;27(05):854-860

30 Brueck M, Kramer W, Vogt P, et al. Antiplatelet therapy early after bioprosthetic aortic valve replacement is unnecessary in patients without thromboembolic risk factors. Eur J Cardiothorac Surg 2007;32(01):108-112

31 Philippart R, Brunet-Bernard A, Clementy N, et al. Oral anticoagulation, stroke and thromboembolism in patients with atrial fibrillation and valve bioprosthesis. The Loire Valley Atrial Fibrillation Project. Thromb Haemost 2016;115(05):1056-1063

32 Durães AR, de Souza Roriz P, de Almeida Nunes B, et al. Dabigatran versus warfarin after bioprosthesis valve replacement for the management of atrial fibrillation postoperatively: DAWA pilot study. Drugs R D 2016;16(02):149-154

33 Yadlapati A, Groh C, Malaisrie SC, et al. Efficacy and safety of novel oral anticoagulants in patients with bioprosthetic valves. Clin Res Cardiol 2016;105(03):268-272

34 Ende G, Sichting L, Pfluecke C, et al. Anticoagulation therapy of patients with atrial fibrillation after TAVI - Dresdner DOAK Register-TAVI (DDRT). Eur Heart J 2015;36(Suppl 1):343

35 Iung B, Baron G, Butchart EG, et al. A prospective survey of patients with valvular heart disease in Europe: The Euro Heart Survey on Valvular Heart Disease. Eur Heart J 2003;24(13):1231-1243

36 Butchart EG, Gohlke-Bärwolf C, Antunes MJ, et al; Working Groups on Valvular Heart Disease, Thrombosis, and Cardiac Rehabilitation and Exercise Physiology, European Society of Cardiology. Recommendations for the management of patients after heart valve surgery. Eur Heart J 2005;26(22):2463-2471

37 Camm AJ, Kirchhof P, Lip GY, et al; European Heart Rhythm Association; European Association for Cardio-Thoracic Surgery. Guidelines for the management of atrial fibrillation: the Task Force for the Management of Atrial Fibrillation of the European Society of Cardiology (ESC). Eur Heart J 2010;31(19):2369-2429

38 Nishimura RA, Otto CM, Bonow RO, et al; ACC/AHA Task Force Members. 2014 AHA/ACC Guideline for the Management of Patients with Valvular Heart Disease: executive summary: a report of the American College of Cardiology/American Heart Association Task Force on Practice Guidelines. Circulation 2014; 129(23):2440-2492
39 Oxenham H, Bloomfield P, Wheatley DJ, et al. Twenty year comparison of a Bjork-Shiley mechanical heart valve with porcine bioprostheses. Heart 2003;89(07):715-721

40 Whitlock RP, Sun JC, Fremes SE, Rubens FD, Teoh KH. Antithrombotic and thrombolytic therapy for valvular disease: Antithrombotic Therapy and Prevention of Thrombosis, 9th ed: American College of Chest Physicians Evidence-Based Clinical Practice Guidelines. Chest 2012;141(2, Suppl):e576S-e600S

41 Turpie AG, Gent M, Laupacis A, et al. A comparison of aspirin with placebo in patients treated with warfarin after heart-valve replacement. N Engl J Med 1993;329(08):524-529

42 Laffort P, Roudaut R, Roques X, et al. Early and long-term (one-year) effects of the association of aspirin and oral anticoagulant on thrombi and morbidity after replacement of the mitral valve with the St. Jude medical prosthesis: a clinical and transesophageal echocardiographic study. J Am Coll Cardiol 2000;35(03):739-746

43 Massel DR, Little SH. Antiplatelet and anticoagulation for patients with prosthetic heart valves. Cochrane Database Syst Rev 2013;7(07):CD003464

44 Larson RJ, Fisher ES. Should aspirin be continued in patients started on warfarin? J Gen Intern Med 2004;19(08):879-886

45 Dentali F, Douketis JD, Gianni M, Lim W, Crowther MA. Metaanalysis: anticoagulant prophylaxis to prevent symptomatic venous thromboembolism in hospitalized medical patients. Ann Intern Med 2007;146(04):278-288

46 Dong MF, Ma ZS, Ma SJ, et al. Anticoagulation therapy with combined low dose aspirin and warfarin following mechanical heart valve replacement. Thromb Res 2011;128(05):e91-e94

47 Altman R, Rouvier J, Gurfinkel E, Scazziota A, Turpie AG. Comparison of high-dose with low-dose aspirin in patients with mechanical heart valve replacement treated with oral anticoagulant. Circulation 1996;94(09):2113-2116

48 Meschia JF, Bushnell C, Boden-Albala B, et al; American Heart Association Stroke Council; Council on Cardiovascular and Stroke Nursing; Council on Clinical Cardiology; Council on Functional Genomics and Translational Biology; Council on Hypertension. Guidelines for the primary prevention of stroke: a statement for healthcare professionals from the American Heart Association/ American Stroke Association. Stroke 2014;45(12):3754-3832

49 Nishimura RA, Otto CM, Bonow RO, et al. 2017 AHA/ACC Focused Update of the 2014 AHA/ACC Guideline for the Management of Patients With Valvular Heart Disease: a report of the American College of Cardiology/American Heart Association Task Force on Clinical Practice Guidelines. Circulation 2017;135(25):e1159-e1195

50 Pengo V, Palareti G, Cucchini U, et al; participating centers of Italian Federation of Anticoagulation Clinics (FCSA). Low-intensity oral anticoagulant plus low-dose aspirin during the first six months versus standard-intensity oral anticoagulant therapy after mechanical heart valve replacement: a pilot study of lowintensity warfarin and aspirin in cardiac prostheses (LIWACAP). Clin Appl Thromb Hemost 2007;13(03):241-248

51 Meschengieser SS, Fondevila CG, Frontroth J, Santarelli MT, Lazzari MA. Low-intensity oral anticoagulation plus low-dose aspirin versus high-intensity oral anticoagulation alone: a randomized trial in patients with mechanical prosthetic heart valves. J Thorac Cardiovasc Surg 1997;113(05):910-916

52 Eikelboom JW, Hirsh J. Combined antiplatelet and anticoagulant therapy: clinical benefits and risks. J Thromb Haemost 2007;5 (Suppl 1):255-263

53 Connolly SJ, Ezekowitz MD, Yusuf S, et al; RE-LY Steering Committee and Investigators. Dabigatran versus warfarin in patients with atrial fibrillation. N Engl J Med 2009;361(12):1139-1151

54 Patel MR, Mahaffey KW, Garg J, et al; ROCKET AF Investigators. Rivaroxaban versus warfarin in nonvalvular atrial fibrillation. N Engl J Med 2011;365(10):883-891

55 Granger CB, Alexander JH, McMurray JJ, et al; ARISTOTLE Committees and Investigators. Apixaban versus warfarin in patients with atrial fibrillation. N Engl J Med 2011;365(11):981-992 
56 Giugliano RP, Ruff CT, Braunwald E, et al; ENGAGE AF-TIMI 48 Investigators. Edoxaban versus warfarin in patients with atrial fibrillation. N Engl J Med 2013;369(22):2093-2104

57 Connolly SJ, Eikelboom J, Joyner C, et al; AVERROES Steering Committee and Investigators. Apixaban in patients with atrial fibrillation. N Engl J Med 2011;364(09):806-817

58 Ezekowitz MD, Nagarakanti R, Noack H, et al. Comparison of dabigatran and warfarin in patients with atrial fibrillation and valvular heart disease: the RE-LY Trial (Randomized Evaluation of Long-Term Anticoagulant Therapy). Circulation 2016;134(08):589-598

59 Breithardt G, Baumgartner H, Berkowitz SD, et al; ROCKET AF Steering Committee \& Investigators. Clinical characteristics and outcomes with rivaroxaban vs. warfarin in patients with nonvalvular atrial fibrillation but underlying native mitral and aortic valve disease participating in the ROCKET AF trial. Eur Heart J 2014;35(47):3377-3385

60 Avezum A, Lopes RD, Schulte PJ, et al. Apixaban in comparison with warfarin in patients with atrial fibrillation and valvular heart disease: findings from the Apixaban for Reduction in Stroke and Other Thromboembolic Events in Atrial Fibrillation (ARISTOTLE) Trial. Circulation 2015;132(08):624-632

61 Lip GY, Laroche C, Dan GA, et al. A prospective survey in European Society of Cardiology member countries of atrial fibrillation management: baseline results of EURObservational Research Programme Atrial Fibrillation (EORP-AF) Pilot General Registry. Europace 2014;16(03):308-319

62 Breithardt G, Baumgartner H, Berkowitz SD, et al; ROCKET AF Steering Committee \& Investigators. Native valve disease in patients with non-valvular atrial fibrillation on warfarin or rivaroxaban. Heart 2016;102(13):1036-1043

63 Renda G, Ricci F, Giugliano RP, De Caterina R. Non-vitamin K antagonist oral anticoagulants in patients with atrial fibrillation and valvular heart disease. J Am Coll Cardiol 2017;69(11):1363-1371

64 Siontis KC, Yao X, Gersh BJ, Noseworthy PA. Direct oral anticoagulants in patients with atrial fibrillation and valvular heart disease other than significant mitral stenosis and mechanical valves: a meta-analysis. Circulation 2017;135(07):714-716

65 Thompson JL, Hamner CE, Potter DD, Lewin M, Sundt TM, Schaff HV. Melagatran for thromboprophylaxis after mechanical valve implantation: results in a heterotopic porcine model. J Thorac Cardiovasc Surg 2007;134(02):359-365

66 McKellar SH, Abel S, Camp CL, Suri RM, Ereth MH, Schaff HV. Effectiveness of dabigatran etexilate for thromboprophylaxis of mechanical heart valves. J Thorac Cardiovasc Surg 2011;141(06):1410-1416

67 Schomburg JL, Medina EM, Lahti MT, Bianco RW. Dabigatran versus warfarin after mechanical mitral valve replacement in the swine model. J Invest Surg 2012;25(03):150-155

68 Eikelboom JW, Connolly SJ, Brueckmann M, et al; RE-ALIGN Investigators. Dabigatran versus warfarin in patients with mechanical heart valves. N Engl J Med 2013;369(13):1206-1214

69 Jaffer IH, Stafford AR, Fredenburgh JC, Whitlock RP, Chan NC, Weitz JI. Dabigatran is less effective than warfarin at attenuating mechanical heart valve-induced thrombin generation. J Am Heart Assoc 2015;4(08):e002322

70 Nombela-Franco L, Webb JG, de Jaegere PP, et al. Timing, predictive factors, and prognostic value of cerebrovascular events in a large cohort of patients undergoing transcatheter aortic valve implantation. Circulation 2012;126(25):3041-3053

71 Stortecky S, Buellesfeld L, Wenaweser P, et al. Atrial fibrillation and aortic stenosis: impact on clinical outcomes among patients undergoing transcatheter aortic valve implantation. Circ Cardiovasc Interv 2013;6(01):77-84

72 Pokorney SD, Rao MP, Wojdyla DM, et al. Apixaban use in patients with atrial fibrillation with bioprosthetic valves: insights from ARISTOTLE. Circulation 2015;132:A17277

73 Cayla G, Hulot JS, O'Connor SA, et al. Clinical, angiographic, and genetic factors associated with early coronary stent thrombosis. JAMA 2011;306(16):1765-1774
74 Abdul-Jawad Altisent O, Durand E, Muñoz-García AJ, et al. Warfarin and antiplatelet therapy versus warfarin alone for treating patients with atrial fibrillation undergoing transcatheter aortic valve replacement. JACC Cardiovasc Interv 2016;9(16):1706-1717

75 Dewilde WJ, Oirbans T, Verheugt FW, et al; WOEST study investigators. Use of clopidogrel with or without aspirin in patients taking oral anticoagulant therapy and undergoing percutaneous coronary intervention: an open-label, randomised, controlled trial. Lancet 2013;381(9872):1107-1115

76 Schulz-Schüpke S, Byrne RA, Ten Berg JM, et al; Intracoronary Stenting and Antithrombotic Regimen: Safety And EFficacy of 6 Months Dual Antiplatelet Therapy After Drug-Eluting Stenting (ISAR-SAFE) Trial Investigators. ISAR-SAFE: a randomized, double-blind, placebo-controlled trial of 6 vs. 12 months of clopidogrel therapy after drug-eluting stenting. Eur Heart J 2015;36(20): 1252-1263

77 Urban P, Meredith IT, Abizaid A, et al; LEADERS FREE Investigators. Polymer-free drug-coated coronary stents in patients at high bleeding risk. N Engl J Med 2015;373(21):2038-2047

78 Connolly SJ, Pogue J, Eikelboom J, et al; ACTIVE W Investigators. Benefit of oral anticoagulant over antiplatelet therapy in atrial fibrillation depends on the quality of international normalized ratio control achieved by centers and countries as measured by time in therapeutic range. Circulation 2008; 118(20):2029-2037

79 Makkar RR, Fontana G, Jilaihawi H, et al. Possible subclinical leaflet thrombosis in bioprosthetic aortic valves. N Engl J Med 2015;373(21):2015-2024

80 Seeger J, Gonska B, Rodewald C, Rottbauer W, Wöhrle J. Apixaban in patients with atrial fibrillation after transfemoral aortic valve replacement. JACC Cardiovasc Interv 2017;10(01):66-74

81 Holmes DR Jr, Kar S, Price MJ, et al. Prospective randomized evaluation of the Watchman Left Atrial Appendage Closure device in patients with atrial fibrillation versus long-term warfarin therapy: the PREVAIL trial. J Am Coll Cardiol 2014;64(01):1-12

82 Holmes DR, Reddy VY, Turi ZG, et al; PROTECT AF Investigators. Percutaneous closure of the left atrial appendage versus warfarin therapy for prevention of stroke in patients with atrial fibrillation: a randomised non-inferiority trial. Lancet 2009;374(9689):534-542

83 Price MJ, Reddy VY, Valderrábano M, et al. Bleeding outcomes after left atrial appendage closure compared with long-term warfarin: a pooled, patient-level analysis of the WATCHMAN randomized trial experience. JACC Cardiovasc Interv 2015;8(15):1925-1932

84 Patti G, Pengo V, Marcucci R, et al; Working Group of Thrombosis of the Italian Society of Cardiology. The left atrial appendage: from embryology to prevention of thromboembolism. Eur Heart J 2017;38(12):877-887

85 Bösche LI, Afshari F, Schöne D, Ewers A, Mügge A, Gotzmann M. Initial experience with novel oral anticoagulants during the first 45 days after left atrial appendage closure with the Watchman device. Clin Cardiol 2015;38(12):720-724

86 Reddy VY, Möbius-Winkler S, Miller MA, et al. Left atrial appendage closure with the Watchman device in patients with a contraindication for oral anticoagulation: the ASAP study (ASA Plavix Feasibility Study With Watchman Left Atrial Appendage Closure Technology). J Am Coll Cardiol 2013;61(25):2551-2556

87 Bax JJ, Delgado V, Bapat V, et al. Open issues in transcatheter aortic valve implantation. Part 1: patient selection and treatment strategy for transcatheter aortic valve implantation. Eur Heart J 2014;35(38):2627-2638

88 Bax JJ, Delgado V, Bapat V, et al. Open issues in transcatheter aortic valve implantation. Part 2: procedural issues and outcomes after transcatheter aortic valve implantation. Eur Heart J 2014;35(38):2639-2654

89 Heidbuchel H, Verhamme P, Alings M, et al. Updated European Heart Rhythm Association Practical Guide on the use of nonvitamin K antagonist anticoagulants in patients with non-valvular atrial fibrillation. Europace 2015;17(10):1467-1507 
90 Lip GY, Windecker S, Huber K, et al; Document Reviewers. Management of antithrombotic therapy in atrial fibrillation patients presenting with acute coronary syndrome and/or undergoing percutaneous coronary or valve interventions: a joint consensus document of the European Society of Cardiology Working Group on Thrombosis, European Heart Rhythm Association (EHRA), European Association of Percutaneous Cardiovascular Interventions (EAPCI) and European Association of Acute Cardiac Care (ACCA) endorsed by the Heart Rhythm Society (HRS) and Asia-Pacific Heart Rhythm Society (APHRS). Eur Heart J 2014;35(45):3155-3179

91 Holmes DR Jr, Mack MJ, Kaul S, et al; American Heart Association; American Society of Echocardiography; European Association for Cardio-Thoracic Surgery; Heart Failure Society of America; Mended Hearts; Society of Cardiovascular Anesthesiologists; Society of Cardiovascular Computed Tomography; Society for Cardiovascular Magnetic Resonance. 2012 ACCF/AATS/SCAI/STS expert consensus document on transcatheter aortic valve replacement: developed in collaboration with the American Heart Association, American Society of Echocardiography, European Association for Cardio-Thoracic Surgery, Heart Failure Society of America, Mended Hearts, Society of Cardiovascular Anesthesiologists, Society of Cardiovascular Computed Tomography, and Society for Cardiovascular Magnetic Resonance. J Thorac Cardiovasc Surg 2012;144(03):e29-e84

92 Webb J, Rodés-Cabau J, Fremes S, et al. Transcatheter aortic valve implantation: a Canadian Cardiovascular Society position statement. Can J Cardiol 2012;28(05):520-528

93 Sliwa K, Johnson MR, Zilla P, Roos-Hesselink JW. Management of valvular disease in pregnancy: a global perspective. Eur Heart J 2015;36(18):1078-1089

94 Alshawabkeh L, Economy KE, Valente AM. Anticoagulation during pregnancy: evolving strategies with a focus on mechanical valves. J Am Coll Cardiol 2016;68(16):1804-1813

95 van Hagen IM, Roos-Hesselink JW, Ruys TP, et al; ROPAC Investigators and the EURObservational Research Programme (EORP) Team*. Pregnancy in women with a mechanical heart valve: data of the European Society of Cardiology Registry of Pregnancy and Cardiac Disease (ROPAC). Circulation 2015;132 (02):132-142

$96 \mathrm{XuZ}$, Fan J, Luo X, et al. Anticoagulation regimens during pregnancy in patients with mechanical heart valves: a systematic review and meta-analysis. Can J Cardiol 2016;32(10):1248.e1-1248.e9

97 Vahanian A, Alfieri O, Andreotti F, et al; ESC Committee for Practice Guidelines (CPG); Joint Task Force on the Management of Valvular Heart Disease of the European Society of Cardiology (ESC); European Association for Cardio-Thoracic Surgery (EACTS). Guidelines on the management of valvular heart disease (version 2012): the Joint Task Force on the Management of Valvular Heart Disease of the European Society of Cardiology (ESC) and the European Association for Cardio-Thoracic Surgery (EACTS). Eur J Cardiothorac Surg 2012;42(04):S1-S44

98 Desai CS, Bonow RO. Transcatheter valve replacement for aortic stenosis: balancing benefits, risks, and expectations. JAMA 2012; 308(06):573-574

99 Tillquist MN, Maddox TM. Cardiac crossroads: deciding between mechanical or bioprosthetic heart valve replacement. Patient Prefer Adherence 2011;5:91-99

100 Lindman BR, Alexander KP, O'Gara PT, Afilalo J. Futility, benefit, and transcatheter aortic valve replacement. JACC Cardiovasc Interv 2014;7(07):707-716

101 Charles C, Gafni A, Whelan T. Shared decision-making in the medical encounter: what does it mean? (or it takes at least two to tango). Soc Sci Med 1997;44(05):681-692

102 Charles C, Gafni A, Whelan T. How to improve communication between doctors and patients. Learning more about the decision making context is important. BMJ 2000;320(7244): $1220-1221$
103 Malloy-Weir LJ, Charles C, Gafni A, Entwistle VA. Empirical relationships between health literacy and treatment decision making: a scoping review of the literature. Patient Educ Couns 2015;98(03):296-309

104 Coylewright M, Palmer R, O'Neill ES, Robb JF, Fried TR. Patientdefined goals for the treatment of severe aortic stenosis: a qualitative analysis. Health Expect 2016;19(05):1036-1043

105 Hussain AI, Garratt AM, Brunborg C, Aakhus S, Gullestad L, Pettersen KI. Eliciting patient risk willingness in clinical consultations as a means of improving decision-making of aortic valve replacement. J Am Heart Assoc 2016;5(03):e002828

106 Birkmeyer NJ, Birkmeyer JD, Tosteson AN, Grunkemeier GL, Marrin CA, O'Connor GT. Prosthetic valve type for patients undergoing aortic valve replacement: a decision analysis. Ann Thorac Surg 2000;70(06):1946-1952

107 Takkenberg JJ, Puvimanasinghe JP, van Herwerden LA, et al. Decision-making in aortic valve replacement: bileaflet mechanical valves versus stented bioprostheses. Neth Heart J 2003;11(01): $5-10$

108 Lip GYH, Brechin CM, Lane DA. The global burden of atrial fibrillation and stroke: a systematic review of the epidemiology of atrial fibrillation in regions outside North America and Europe. Chest 2012;142(06):1489-1498

109 Narasimhan CVJ, Kishore AGR, Singh B, et al. The REALIZE AF study. An International, Observational Cross Sectional Survey Evaluating AF Management and Cardiovascular Risk Profile of AF Patients, Indian Subset Data Presented at the ISE Meeting, Jaipur, India; 2012

110 Zühlke L, Engel ME, Karthikeyan G, et al. Characteristics, complications, and gaps in evidence-based interventions in rheumatic heart disease: the Global Rheumatic Heart Disease Registry (the REMEDY study). Eur Heart J 2015;36(18):1115-22a

111 Narasimhan C, Verma JS, Ravi Kishore AG, et al. Cardiovascular risk profile and management of atrial fibrillation in India: Real world data from RealiseAF survey. Indian Heart J 2016;68(05): 663-670

112 Egbe AC, Pislaru SV, Pellikka PA, et al. Bioprosthetic valve thrombosis versus structural failure: clinical and echocardiographic predictors. J Am Coll Cardiol 2015;66(21):2285-2294

113 Vora A, Kapoor A, Nair M, et al. Clinical presentation, management, and outcomes in the Indian Heart Rhythm Society-Atrial Fibrillation (IHRS-AF) registry. Indian Heart J 2017;69(01):43-47

114 Marcolino MS, Polanczyk CA, Bovendorp AC, et al. Economic evaluation of the new oral anticoagulants for the prevention of thromboembolic events: a cost-minimization analysis. Sao Paulo Med J 2016;134(04):322-329

115 Maniadakis N, Vardas P, Mantovani LG, Fattore G, Boriani G. Economic evaluation in cardiology. Europace 2011;13(Suppl 2): ii3-ii8

116 Boriani G, Maniadakis N, Auricchio A, et al. Health technology assessment in interventional electrophysiology and device therapy: a position paper of the European Heart Rhythm Association. Eur Heart J 2013;34(25):1869-1874

117 Wolowacz SE, Samuel M, Brennan VK, Jasso-Mosqueda JG, Van Gelder IC. The cost of illness of atrial fibrillation: a systematic review of the recent literature. Europace 2011;13(10): 1375-1385

118 Boriani G, Diemberger I, Biffi M, Martignani C. Balancing the risk of hemorrhage vs thromboembolism in patients with atrial fibrillation: how to navigate between Scylla and Charybdis? Chest 2010;138(05):1032-1033

119 Kirchhof P, Breithardt G, Bax J, et al. A roadmap to improve the quality of atrial fibrillation management: proceedings from the fifth Atrial Fibrillation Network/European Heart Rhythm Association consensus conference. Europace 2016;18(01):37-50

120 Brüggenjürgen $\mathrm{B}$, Rossnagel $\mathrm{K}$, Roll S, et al. The impact of atrial fibrillation on the cost of stroke: the berlin acute stroke study. Value Health 2007;10(02):137-143 
121 Cotté FE, Chaize G, Kachaner I, Gaudin AF, Vainchtock A, DurandZaleski I. Incidence and cost of stroke and hemorrhage in patients diagnosed with atrial fibrillation in France. J Stroke Cerebrovasc Dis 2014;23(02):e73-e83

122 Mercaldi CJ, Siu K, Sander SD, et al. Long-term costs of ischemic stroke and major bleeding events among Medicare patients with nonvalvular atrial fibrillation. Cardiol Res Pract 2012; 2012:645469

123 Casciano JP, Dotiwala ZJ, Martin BC, Kwong WJ. The costs of warfarin underuse and nonadherence in patients with atrial fibrillation: a commercial insurer perspective. J Manag Care Pharm 2013;19(04):302-316

124 Beyer-Westendorf J, Ehlken B, Evers T. Real-world persistence and adherence to oral anticoagulation for stroke risk reduction in patients with atrial fibrillation. Europace 2016;18(08):1150-1157

125 Boriani G, Cimaglia P, Fantecchi E, et al. Non-valvular atrial fibrillation: potential clinical implications of the heterogeneous definitions used in trials on new oral anticoagulants. J Cardiovasc Med (Hagerstown) 2015;16(07):491-496
126 Philippart R, Brunet-Bernard A, Clementy N, et al. Prognostic value of CHA2DS2-VASc score in patients with 'non-valvular atrial fibrillation' and valvular heart disease: the Loire Valley Atrial Fibrillation Project. Eur Heart J 2015;36(28):1822-1830

127 Kasmeridis C, Apostolakis S, Ehlers L, Rasmussen LH, Boriani G, Lip GY. Cost effectiveness of treatments for stroke prevention in atrial fibrillation: focus on the novel oral anticoagulants. Pharmacoeconomics 2013;31(11):971-980

128 Janzic A, Kos M. Cost effectiveness of novel oral anticoagulants for stroke prevention in atrial fibrillation depending on the quality of warfarin anticoagulation control. Pharmacoeconomics 2015;33(04):395-408

129 Hemmrich M, Peterson ED, Thomitzek K, Weitz JI. Spotlight on unmet needs in stroke prevention: The PIONEER AF-PCI, NAVIGATE ESUS and GALILEO trials. Thromb Haemost 2016;116 (Suppl 2):S33-S40

130 Gargiulo G, Collet JP, Valgimigli M. Antithrombotic therapy in TAVI patients: changing concepts. EuroIntervention 2015;11 (Suppl W):W92-5 